\title{
DESENVOLVIMENTO DE UM AMBIENTE WEB PARA A INTERAÇÃO ENTRE PARTICIPANTES DE PROJETOS DE AGRICULTURA DE PRECISÃO
}

\section{WLADIMIR PENA CAMARGO}

Dissertação apresentada à Escola Superior de Agricultura "Luiz de Queiroz", Universidade de São Paulo, para obtenção do título de Mestre em Agronomia, Área de Concentração: Máquinas Agrícolas.

P I R A C I C A B A

Estado de São Paulo - Brasil

Março - 2005 


\title{
DESENVOLVIMENTO DE UM AMBIENTE WEB PARA A INTERAÇÃO ENTRE PARTICIPANTES DE PROJETOS DE AGRICULTURA DE PRECISÃO
}

\author{
WLADIMIR PENA CAMARGO \\ Engenheiro Agrônomo
}

Orientador: Prof. Dr. JORGE GUSTAVO DA GRAÇA RAFFO

\begin{abstract}
Dissertação apresentada à Escola Superior de Agricultura "Luiz de Queiroz", Universidade de São Paulo, para obtenção do título de Mestre em Agronomia, Área de Concentração: Máquinas Agrícolas.
\end{abstract}

P I R A C I C A B A

Estado de São Paulo - Brasil

Março - 2005 
Dados Internacionais de Catalogação na Publicação (CIP) DIVISÃO DE BIBLIOTECA E DOCUMENTAÇÃO - ESALQ/USP

\section{Camargo, Wladimir Pena}

Desenvolvimento de um ambiente Web para a interação entre participantes de projetos de agricultura de precisão / Wladimir Pena Camargo. - - Piracicaba, 2005. 59 p. : il.

Dissertação (mestrado) - - Escola Superior de Agricultura Luiz de Queiroz, 2005. Bibliografia.

1. Agricultura de precisão 2. Internet 3. Redes de computadores 4. Sistema de Informação Geográfica 5. Software 6. Tecnologia da informação I. Título

CDD 631.3

"Permitida a cópia total ou parcial deste documento, desde que citada a fonte - O autor" 


\section{DEDICATÓRIA}

Ao meu pai Pedro de Camargo pelo incentivo, apoio e, sobretudo, por servir de inspiração para trilhar minha vida acadêmica.

Às mulheres da minha vida: minha mãe Maria Célia de Castro Pena, minha namorada Danúbia e minha irmã Janaina.

Dedico a todos com muito carinho. 


\section{AGRADECIMENTOS}

Agradeço ao meu orientador Jorge Gustavo da Graça Raffo pela amizade, confiança e pelo valioso aconselhamento durante a elaboração desta dissertação.

Ao amigo Luiz Fernando Albertin Maria pelo incentivo à incursão no mundo da tecnologia web.

À Unioncobra Assessoria de Cobranças pelo apoio.

Aos amigos Cristian Moroz, André Conz, Fabio Burdignon e Fernando Pardo pelo incentivo e alegria.

Aos colegas do curso de pós-graduação em Máquinas Agrícolas. 


\section{SUMÁRIO}

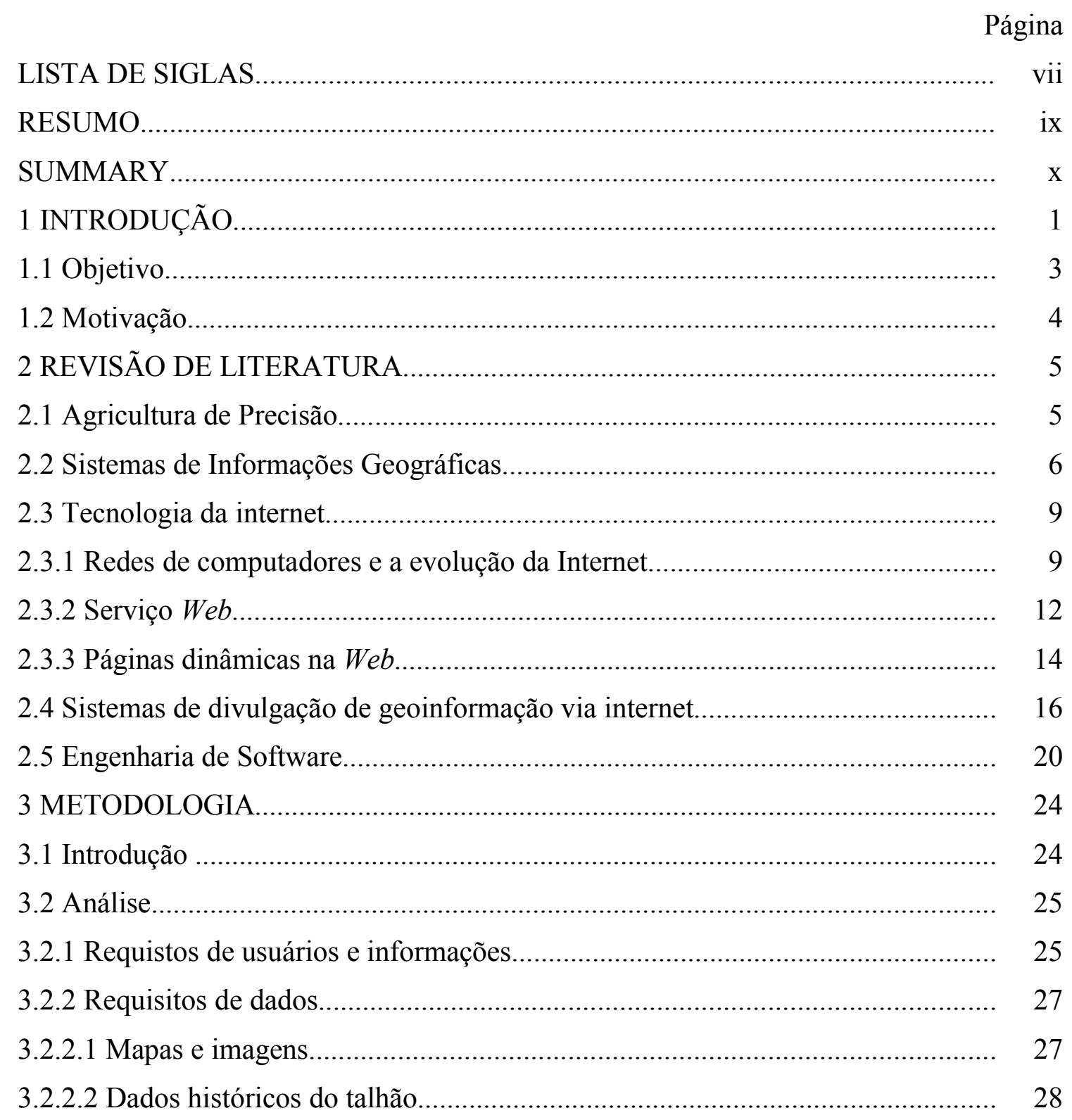


3.2.2.3 Arquivos de dados diversos................................................................. 28

3.2.3 Requisitos de interface do usuário................................................................. 30

3.2.4 Requisitos de acesso e segurança.................................................................. 31

3.2.5 Requisitos de comunicação........................................................................... 32

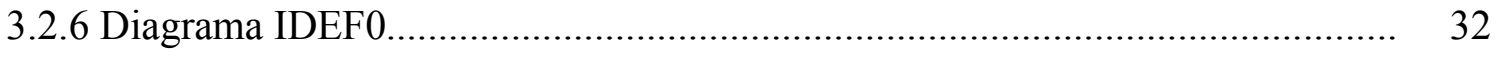

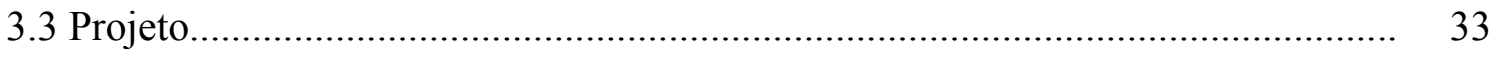

3.3.1 Estrutura e funcionamento do sistema........................................................ 35

3.3.2 Modelagem do banco de dados................................................................ 36

3.3.3 Modelagem do Sistema.......................................................................... 37

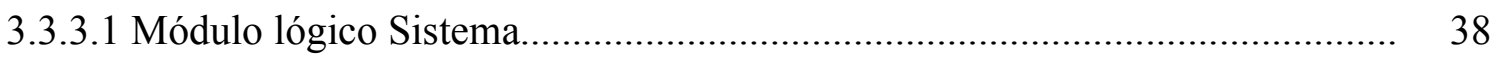

3.3.3.2 Módulo lógico Mapas.................................................................................. 39

3.3.3.3 Módulo lógico Dados............................................................................ 40

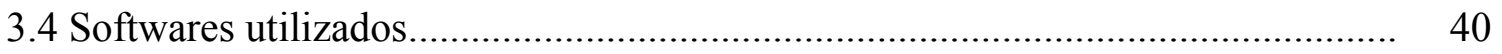

4 RESULTADOS E DISCUSSÃO................................................................. 41

4.1 Exemplos de uso de um usuário não especialista................................................ 41

4.2 Exemplos de uso de um usuário especialista...................................................... 47

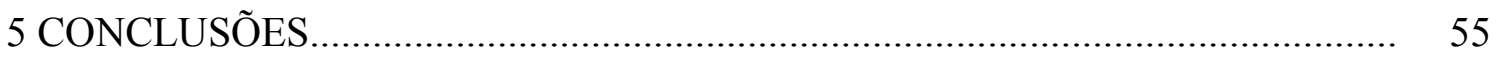

REFERÊNCIAS BIBLIOGRÁFICAS_............................................................. 57 


\section{LISTA DE SIGLAS}

AP-Agricultura de Precisão

CGI - Common Gateway Interface. Interface para troca de dados entre aplicações

ESRI - Environmental Systems Research Institute. Empresa desenvolvedora de softwares para uso de mapas digitais e sistemas computadorizados de informações geográficas

GPL - General Public License

GPS - Global Positioning System - Sistema de Posicionamento Global por satélite

HTML - Hypertext Markup Language. Linguagem de formatação de hipertexto

HTTP - Hypertext Transfer Protocol. Protocolo para transferência de arquivos na internet

IDEF - Integration Definition for Function Modelling

IP - Internet Protocol

ISP - Internet Service Provider. Provedor de serviços Internet

Kbps - Kilo bits per second (milhares de bits por segundo). Unidade utilizada para medir a taxa de transferência de dados por segundo entre dispositivos em redes de computadores.

Modem - Modulador e demodulador. Dispositivo para transmissão de dados digitais em canais analógicos como linhas telefônicas

Navegador $\boldsymbol{W e b}$ - é o programa que exibe uma página escrita em HTML

PHP - Personal Home Page. Linguagem de spript para uso em páginas HTML

PNG - Portable Network Graphics - formato para imagens de 24 bits com compressão sem perdas, idealizado em 1995 para substituir o popular formato GIF que possuía patente em seu formato de compressão

RNP - Rede Nacional de Pesquisa. Órgão gestor da Internet no Brasil 
SGBD - Sistema Gerenciador de Banco de Dados

SIG - Sistema de Informações Geográficas

SQL - Structured Query Language. Linguagem estruturada para consulta de dados

TCP/IP - Transmission Control Protocol/Internet Protocol. Conjunto de protocolos de comunicação utilizado na internet

TIFF- Tagged-Image File Format. Formato de arquivo de imagem raster, muito utilizado em programas gráficos que permite o georreferenciamento

URL - Uniform Resource Locator. Localizador uniforme de recurso, como são chamados os endereços $\mathrm{Web}$

Web - World Wide Web. Sinônimo para páginas multimídia na Internet 


\title{
DESENVOLVIMENTO DE UM AMBIENTE WEB PARA A INTERAÇÃO ENTRE PARTICIPANTES DE PROJETOS DE AGRICULTURA DE PRECISÃO
}

\author{
Autor: WLADIMIR PENA CAMARGO \\ Orientador: Prof. Dr. JORGE GUSTAVO DA GRAÇA RAFFO
}

\section{RESUMO}

Agricultura de Precisão é um novo paradigma de gestão da produção agrícola, que considera as variabilidades da produtividade e dos fatores de produção. Nesse novo paradigma de produção os agrônomos especializados em Agricultura de Precisão utilizam softwares para o gerenciamento de dados e visualização de mapas que são gerados nas diversas fases do processo. Estes softwares são caros e complexos, o que dificulta para os usuários não especialistas o acesso aos mapas, ficando o seu uso restrito apenas ao usuário especializado. O objetivo deste trabalho é o desenvolvimento de um ambiente, com interface amigável e de baixo custo, que opere pela internet, permitindo aos usuários menos especializados a visualização dos mapas e a inserção de informações indexadas aos talhões de produção em uma base de dados remota. Foi desenvolvida uma solução de software utilizando componentes de software livre como o sevidor web Apache, a linguagem interpretada PHP, o módulo do Apache Mapscript e o Banco de Dados MySQL. Para a interação dos usuários com a imagem dos mapas foi proposto e desenvolvido um algorítmo para a criação de pontos clicáveis que são gerados dinamicamente. 


\title{
WEB ENVIRONMENT DEVELOPING FOR PRECISION FARMING PROJECT PARTICIPANTS INTERACTION
}

\author{
Author: WLADIMIR PENA CAMARGO \\ Adviser: Prof. Dr. JORGE GUSTAVO DA GRAÇA RAFFO
}

\section{SUMMARY}

Precision Agriculture is a new paradigm to manage yield variability and the agricultural inputs. The agricultural engineer specialized in Precision Farming uses softwares to manage data and to visualize maps that are made in the many steps of the process. These softwares are expensive and complex and, thus, dificult to those users who are not specialized in accessing the maps. The aim of this work is to develop a system, with a friendly-user and low cost interface, that operates through the internet, allowing unspecialized users to visualize those maps and to insert field indexed information in a remote database. A software was developed using free components like Apache webserver, PHP script language, Mapscript Apache's module and the Mysql database. For the user interaction with the map image, a algoritm to dinamicly create link points was proposed and developed. 


\section{INTRODUÇÃO}

A crescente preocupação com o ambiente e a pressão pela qualidade e sustentabilidade da produção agropecuária demandam uma modernização da gestão da atividade agrícola. A gestão agrícola moderna, por sua vez, está associada ao desenvolvimento da Tecnologia da Informação, que torna possível a manipulação de um grande número de variáveis envolvidas no processo produtivo e dinamiza os processos de tomada de decisão e de busca, obtenção e troca de informações.

Dentro deste contexto, surge a Agricultura de Precisão - AP, um novo paradigma de gestão da produção agropecuária, que considera as variabilidades espaciais e temporais da produtividade e dos fatores de produção. A aplicação deste novo paradigma no campo resultou em um pacote tecnológico que utiliza tecnologias como a eletrônica embarcada, as máquinas para aplicação de insumos a taxas variáveis, os receptores de GPS - Global Positioning System com correção diferencial e outros recursos.

A Tecnologia da Informação atua basicamente em três etapas básicas da Agricultura de Precisão: coleta de dados, gerenciamento da informação e atuação em campo. O gerenciamento da informação é o elo entre a coleta de dados e as ações localizadas, e é nesta fase que são analisados os dados coletados para a obtenção de informações que alimentem a tomada de decisão de manejo, culminando em um mapa de prescrição de insumo.

Esta etapa conjuga um grande conjunto de operações e análises, como por exemplo, a correção e filtragem de dados produtividade, análises geoestatísticas, análises de correlações entre mapas, armazenamento e a recuperação de informações, geração de mapa de prescrição, etc. Ela é realizada por agrônomos que possuem conhecimento que ultrapassa aqueles adquiridos em uma faculdade de Agronomia e se estendem por outras áreas do conhecimento como geodésia, cartografia, geoestatística, etc. 
A grande maioria das operações realizadas nesta etapa são suportadas por Sistemas de Informações Geográficas que geralmente são complexos e caros.

Estas características dos pacotes de tecnologia de AP dificultam para os usuários não especialistas a manipulação e a visualização dos dados nesta fase de análise, ficando o seu uso restrito apenas ao usuário especializado. Um outro aspecto é o custo de aquisição de softwares e treinamento para o acesso aos dados.

No entanto, com o advento da comunicação dos computadores interligados por redes, e principalmente pela internet, abre-se uma nova forma de compartilhamento de dados e informações, podendo existir assim uma interface entre os usuários especializados e os usuários comuns. Dessa forma, torna-se menos restrito o processo de tomada de decisão e mais aberto à contribuição de outros participantes (além dos agrônomos especializados) que figuram no sistema produtivo agrícola, como por exemplo técnicos agrícolas e produtores rurais sem formação técnica.

A partir dessas premissas foi estruturada a proposta deste trabalho: o desenvolvimento de um software, com interface amigável e de baixo custo, que opere pela internet, permitindo que os usuários menos especializados possam visualizar mapas do processo de AP e inserir informações em uma base de dados remota indexadas aos mapas e contribuir com o processo de gerenciamento da informação.

Um software com esses atributos tem como objetivo facilitar o trabalho de empresas especializadas que prestam serviço em AP e também para Institutos de Pesquisas, possibilitando a divulgação de mapas sem a necessidade de o usuário instalar softwares para sua visualização, e incrementando a base de geodados de uma fazenda na medida em que oferece ao produtor e seus empregados uma forma de incluir dados remotamente. 


\subsection{Objetivo}

O presente trabalho tem como objetivo a elaboração de uma abordagem teórica, fundamentada na revisão de literatura existente, e a proposição e o desenvolvimento de uma solução de software, baseada em tecnologia $W e b$, aplicado ao compartilhamento de mapas e informações de Agricultura de Precisão, entre usuários não especialistas e usuários especialistas da área.

Pretende-se criar um ambiente onde os usuários menos especialistas possam interagir de forma remota com um servidor de mapas que contenha geoinformações elaboradas por agrônomos especialistas, e complementarmente, que estes mesmos agrônomos possam recuperar informações básicas da atividade produtiva inseridas pelos usuários menos especializados.

Como objetivos específicos, este trabalho terá as seguintes proposições:

- desenvolver um ambiente onde um usuário possa interagir com mapas utilizando-se apenas de navegadores $W e b$, sem a necessidade instalação de nenhum software adicional no computador do usuário;

- desenvolver uma solução que permita ao usuário, além da simples visualização dos mapas, a gravação de dados que estejam vinculados aos talhões da propriedade agrícola em uma base de dados remota.

- desenvolver um método de interação com mapas baseado na criação dinâmica de pontos clicáveis sobre uma imagem.

Enfim, deseja-se criar um ambiente Web de compartilhamento de geodados aplicado à Agricultura de Precisão.

\subsection{Motivação}

Diversos sofwares estão disponíveis no mercado como ferramentas de apoio à AP. Entre estes, existem desde os programas que acompanham os monitores de produtividade em colhedoras, que permitem uma visualização primária dos dados coletados, até programas específicos para a AP, que possuem diversas funcionalidades em uma interface única. 
Muitos destes pacotes de softwares possuem um número demasiado de recursos que podem torná-los complexos e criar dificuldades para algumas categorias de usuários que não foram treinados para utilizar estas ferramentas.

No entanto, muitos dos potenciais usuários de sistemas de AP poderiam usufruir e até colaborar com este novo paradigma de produção agrícola se pudessem utilizar uma ferramenta mais acessível, com a qual poderiam interagir de forma simplificada com os dados e informações de AP, após a análise dos agrônomos especializados em AP.

Como a maioria dos dados de AP manipulados por estes sistemas possuem um componente espacial, a utilização de um sistema SIG simplificado que possibilitasse a visualização de mapas, poderia promover esta integração de novos usuários.

Além da utilização de um sistema mais simplificado, também é possivel a utilização dos meios de comunicação modernos, como a Internet, para divulgar e propagar estas informações, sendo que as informações armazenadas em bases de dados remotas podem ser acessadas à distância por um grande número de usuários.

Por último, a grande motivação do trabalho é fazer com que o usuário não tenha que instalar programas adicionais em seu computador para o acesso a este ambiente, pois é possível obter esse resultado com a utilização de apenas um programa para navegação na internet. 


\section{REVISÃO DE LITERATURA}

\subsection{Agricultura de Precisão}

De acordo com Balastreire (2001) a Agricultura de Precisão - AP é um conjunto de técnicas que permite o gerenciamento localizado de culturas agrícolas.

Blackmore (2003) define a AP como o termo que descreve a meta de aumentar a eficiência do manejo da agricultura, sendo uma tecnologia em desenvolvimento, que modifica técnicas existentes e incorpora novas ferramentas para o uso do administrador.

Para o autor, o gerenciamento da variabilidade da produção é a parte principal da AP e três tipos dela foram evidenciadas: a espacial, a temporal e a que indica as previsões não realizadas. A variabilidade espacial é a mudança que se observa em uma mesma área de cultivo; a temporal mostra-se como mudanças que ocorrem ano a ano, em um mesmo local da área de cultivo; e a última identifica a discrepância entre a variabilidade prevista e a que realmente ocorreu.

Saraiva (2003) descreve as etapas do processo de AP sob a ótica da informação. Em uma primeira etapa, o objetivo é identificar a variabilidade espacial da produção e dos diversos fatores de produção. Nesta etapa diversos dados são coletados utilizando vários tipos de equipamentos: coletores de dados e amostradores, monitores de produtividade em colhedoras, imagens de satélite, fotos aéreas, etc.

A segunda etapa é o processamento dos dados, onde se busca quantificar a variabilidade e avaliar a sua relevância. Nesta fase tenta-se relacionar a variabilidade da produtividade com a variabilidade dos fatores de produção, buscando relações de causaefeito, com o objetivo de definição de estratégias de manejo que considerem esta variabilidade. 
Como resultado da segunda etapa temos os mapas de prescrição, que indicam e quantificam os insumos a serem aplicadas em campo para cada ponto analisado, levando-se em conta o potencial de produção de cada um.

A terceira etapa consiste na atuação em campo, onde, munidas dos mapas de prescrição, as máquinas podem fazer a aplicação localizada do insumo nas quantidades prescritas. Para que essa aplicação localizada ocorra é necessário que a máquina possua controladores que tenham a capacidade de variar a taxa de aplicação de insumos automaticamente, comandados por um computador de bordo. Este computador de bordo recebe a informação sobre a localização da máquina de um sistema de posicionamento (GPS), consulta o mapa de prescrição, e comanda os atuadores para aplicar as quantidades prescritas.

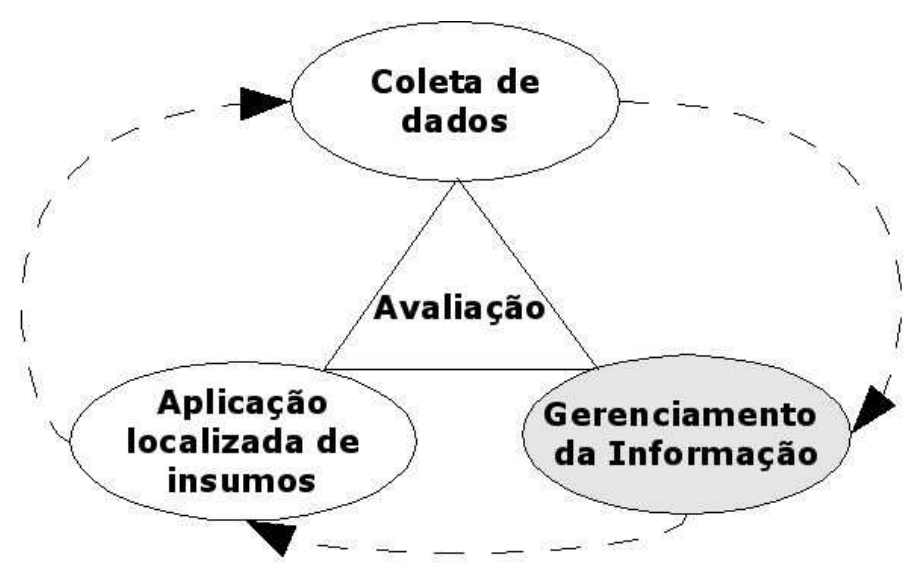

Figura 1 - Etapas da AP, do ponto de vista da informação (Saraiva, 2003)

Na etapa de Gerenciamento da Informação, os Sistemas de Informações Geográfica - SIG, genéricos ou dedicados à AP, são a principal ferramenta utilizada para o estudo e entendimento da variabilidade espacial da produtividade.

\subsection{Sistemas de Informações Geográficas}

Um mapa é a representação feita sobre uma superfície plana de uma região da Terra, mostrando o tamanho relativo e a posição das feições em uma determinada escala ou projeção, e é um importante instrumento para o estudo dos dados geográficos. Estes dados 
geográficos descrevem um objeto do mundo real em termos de sua posição em relação a um sistema de coordenadas conhecidas, da localização geográfica de suas relações espaciais com outros objetos e de suas propriedades medidas ou observadas (Burrough, 1998).

Um dos primeiros exemplos de análise espacial utilizando mapas é o famoso caso da epidemia de cólera em Londres, em 1854 (Câmara, 1995). Na época, não se conhecia a forma de contaminação dessa doença e, após a ocorrência de mais de 500 mortes, John Snow teve uma grande idéia: desenhar em uma mapa da cidade a localização dos doentes que foram afetados pela cólera e os poços que forneciam água aos habitantes da cidade para visualizar a espacialização desses dados.

Com esse mapa, o doutor Snow conseguiu visualizar que a maioria dos casos estava concentrada em torno do poço Broad Street e isso contribuiu para a comprovação da hipótese de transmissão da cólera por ingestão de água contaminada, e para o controle da epidemia.

De acordo com Câmara \& Medeiros (1996) o Geoprocessamento é uma disciplina do conhecimento que utiliza técnicas matemáticas e computacionais para o tratamento de informações geográficas.

A popularização e o barateamento dos computadores pessoais a partir da década de 80, difundiram o uso e o desenvolvimento de Tecnologia da Informação (TI), contribuindo com a evolução do Geoprocessamento.

Os instrumentos computacionais do Geoprocessamento, chamados de Sistemas de Informações Geográficas, permitem a realização de análises complexas ao integrar dados de diversas fontes e ao criar bancos de dados georreferenciados.

Os programas de SIG se diferenciam de outros programas pela capacidade de associar um banco de dados geográficos com um banco de dados de informações cadastrais, no qual estão integradas tecnologias de coleta e tratamento de informações espaciais e análise de dados.

Câmara \& Medeiros (1998) definem SIG como sistemas que efetuam tratamento computacional de dados geográficos. Um SIG armazena a geometria e os atributos dos dados que estão georreferenciados, isto é, localizados na superfície terrestre e numa projeção cartográfica qualquer. 
Segundo Câmara (1995), a estrutura geral de um SIG é composta por: interface com usuário, entrada e integração de dados, funções de processamento gráfico e de imagem, visualização e plotagem e, armazenamento e recuperação de dados.

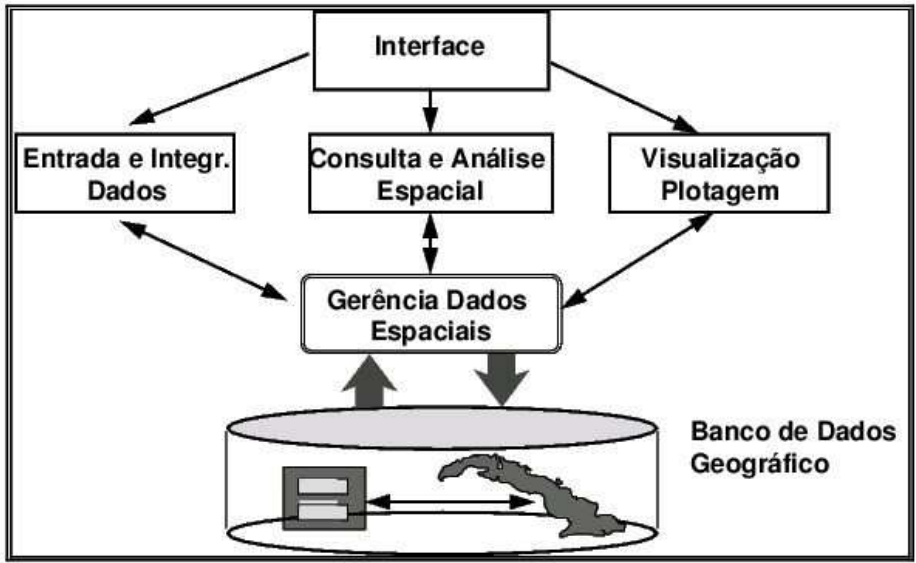

Figura 2 - Arquitetura de um SIG (Câmara, 1995)

Os SIG utilizam um banco de dados geográfico onde são armazenados os dados geográficos ou descritivos. Inicialmente, os SIG armazenavam os dados em arquivos internos e o próprio software era responsável pela manipulação dos dados nestes arquivos. Atualmente os SIG utilizam Sistemas Gerenciadores de Banco de Dados (SGBD) para armazenamento de bases de dados espaciais cada vez maiores (Perez et al., 1997).

Silva (2002) caracteriza os softwares de SIG com relação à arquitetura do Banco de Dados em dois tipos de estruturas: dual e integrada.

A arquitetura dual utiliza dois subsistemas para armazenar a informação geográfica: um sistema gerenciador de banco de dados relacional (SGBDR) para armazenar os atributos descritivos dos objetos geográficos e um sistema gerenciador de dados vetoriais para guardar as representações geométricas destes objetos. Esta é a solução comumente utilizada em SIG voltados para desktops e diversos sistemas consagrados no mercado a utilizam: MGE da Intergraph, Arc/Info da ESRI, Spring do INPE, AutoCad Map e World da AutoDesk, etc. A figura 3 ilustra um exemplo de uma arquitetura dual. 


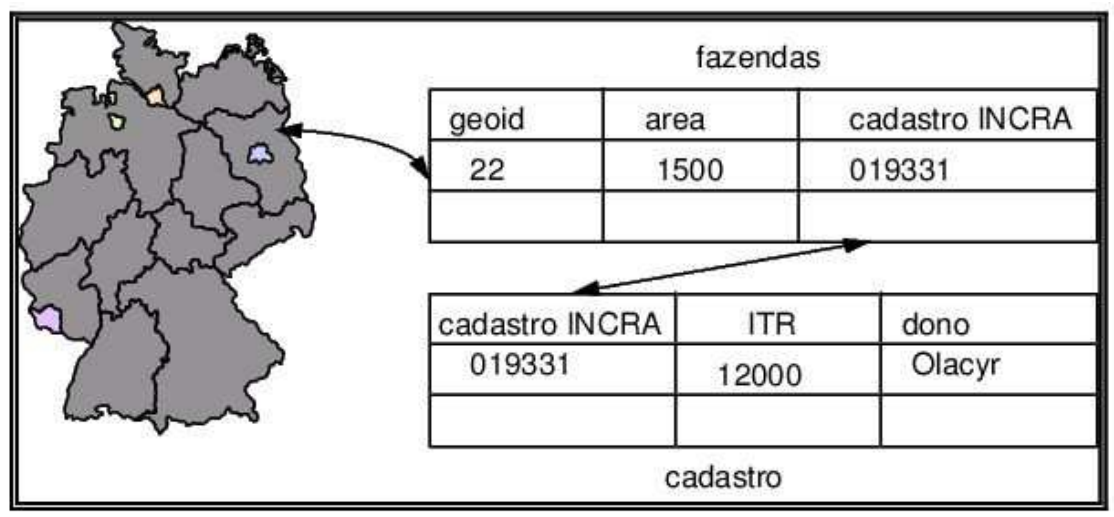

Figura 3 - Exemplo de uma arquitetura dual (adaptado de Câmara, 1995)

$\mathrm{Na}$ arquitetura integrada, o armazenamento da representação geométrica dos objetos geográficos é feita em um campo da tabela de um banco de dados relacional. Nesta arquitetura as informações sobre a representação geométrica do objeto geográfico e seus atributos estão contidas no mesmo local. Esta solução permite a implementação de SIG distribuídos que utilizam uma arquitetura cliente-servidor pois todo o controle de integridade de dados é feito pelo SGDB, permitindo assim a ocorrência de consultas concorrentes. Como exemplo de sistemas que empregam esta arquitetura tem-se: SmallWorld, o GeoMedia da Intergraph e o AutoCad Map.

Há ainda uma terceira arquitetura, descrita por Thomé (1998), que utiliza sistemas gerenciadores de banco de dados orientados por objetos. Nesta arquitetura, chamada de Arquitetura de Campos Extendidos, as representações geométricas e as informações descritivas fazem parte de um objeto geográfico no banco de dados e são recuperadas a partir de métodos definidos internamente pelo SGDB.

\subsection{Tecnologia da internet}

\subsubsection{Redes de computadores e a evolução da Internet}

As redes são formadas quando os computadores são ligados entre si e passam a se comunicar e a trocar informações utilizando uma linguagem comum, conhecida como protocolo de comunicação. 
O TCP/IP, que é o protocolo utilizado por todos os computadores conectados à internet, permite a comunicação entre estes por meio de um conjunto de idéias aparentemente simples: a divisão da informação em pedaços chamados pacotes no computador de origem e a remontagem desses pacotes no computador receptor, configurando desta forma o conceito de rede comutada por pacotes (Itri, 1999).

Os computadores que se comunicam dentro de uma mesma rede não precisam utilizar o mesmo sistema operacional, possibilitando que os diversos ambientes operacionais (como por exemplo, Linux, Microsoft Windows, Mac/OS, OS/2, FreeBSD, Unix, etc) possam conversar a partir do protocolo utilizado na rede.

Cada computador ligado diretamente à rede utilizando o protocolo TCP/IP é chamado de host e recebe um endereço numérico, chamado "endereço IP" (ou simplesmente IP). O IP é composto por quatro números entre 0 e 256 separados por pontos. Além do IP, as máquinas da rede podem também possuir um nome alfanumérico, composto por palavras e números, que é chamado de "nome da máquina". A marioria dos computadores pessoais não possuem esses endereços fixos, isto é, o endereço é atribuído dinamicamente quando o usuário faz uma conexão com seu provedor através de uma conexão de modem discada ou a cabo (Kimball \& Merz, 2000).

A comunicação entre as máquinas de uma rede ocorre sempre utilizando o endereço IP. Quando uma solicitação é feita a partir do nome da máquina, existem computadores especialmente configurados, chamados servidores de nomes (Domain Name Service), que fazem a tradução entre o endereço IP e o endereço alfanumérico.

De acordo com Silva \& Remoaldo (1995), a Internet é freqüentemente descrita como a rede das redes, pois liga diversas redes regionais, nacionais e internacionais, tornando-se a verdadeira rede global . Esta rede evoluiu espontaneamente ao longo dos anos de uma forma anárquica e o ponto de partida para esta evolução ocorreu em 1969, de um projeto do Departamento de Defesa dos Estados Unidos, inicialmente denominada ARPAnet (ARPA - Advanced Research Projetcts Agency), cujo objetivo era possibilitar a interligação de computadores distribuídos em pontos estratégicos, utilizados em centros de investigação com fins militares.

Rapidamente outros locais começaram a ver as vantagens da comunicação eletrônica. Durante os anos 80, continuou a crescer o número de redes que se ligavam 
entre si. Em 1982, a ARPANet juntou-se à MILnet (rede militar), à NFSnet (rede científica da National Science Foundation), e a rede baseada em BBS. A atual internet nasceu da consolidação dessa interligação de redes.

Segundo Itri (1999) o desenvolvimento das redes de computadores começou no Brasil somente em 1988, através de instituições acadêmicas de São Paulo e do Rio de Janeiro que desenvolveram conexões com os EUA através da rede BITNET, dedicada exclusivamente à pesquisa.

Por volta de setembro de 1995 iniciou-se a atividade comercial da rede através de dois tipos de empresas: as gerenciadoras de backbone e as empresa chamadas provedores de acesso (ISP - Internet Service Provider).

As empresas gerenciadoras de backbone são responsáveis pela infra-estrutura de comunicação de dados à longa distância em alta velocidade, chamado de backbone (espinha dorsal em inglês), que ligam os centros regionais de conexão. No Brasil, a Embratel é a gerenciadora de backbone responsável pelo acesso dos usuário a internet para fins comerciais e a RNP é responsável pelo acesso da comunidade acadêmica.

As ISP estão conectadas ao backbone da Embratel através de um link e disponibilizam o acesso à Internet para usuários finais (tanto empresas como pessoas físicas). Esses usuários se ligam ao ISP por meio de uma conexão, que é classificada em conexão permanente (ou dedicada) ou conexão temporária.

Essas conexões provêem ao usuário o acesso à internet, que pode ser de dois tipos: acesso completo e acesso limitado. O acesso completo ocorre quando o computador do usuário possui um endereço de IP válido na internet, tornando-se um nó nesta rede. $\mathrm{O}$ acesso limitado ocorre quando um computador não possui um IP válido na rede, e o seu acesso à internet é compartilhado com outras máquinas através de um roteador.

A velocidade destas conexões entre os usuários finais e ISP varia de acordo com os dispositivos e tecnologias utilizadas na conexão. Utilizando as conexões discadas por modems, que é a forma mais antiga de se conectar à rede e a mais acessível para o grande público, atinge-se uma velocidade de acesso de no máximo 56 kilobits por segundo, dependendo do tipo de modem e da qualidade dessa linha telefônica. Já com o 
uso de tecnologias de banda larga (Cable Modem, ADSL, fibra ótica, etc) esta velocidade é bem mais elevada.

Além da velocidade da própria conexão do usuário existem outros fatores que influenciam na velocidade dos sistemas que usam a internet como meio de comunicação, como por exemplo a velocidade de processamento do servidor que envia suas informações, a velocidade da conexão entre o servidor onde estão suas informações e a Internet e o volume de dados enviados em cada transação.

\subsubsection{Serviço Web}

O crescimento do número de usuários na Internet foi influenciado pela capacidade da rede de permitir a interação de diferentes softwares e plataformas através do protocolo TCP/IP.

Esta característica fez surgir então o modelo cliente-servidor ${ }^{1}$ de aplicação, onde um computador é chamado cliente ou servidor em função da atividade que desenvolve: a de solicitante (cliente) ou a de provedor de serviços (servidor). Um sistema pode ser alternadamente cliente ou servidor, ora provendo serviços, ora requisitando serviços. No entando, com o objetivo de se otimizar a relação custo/benefício em aplicações voltadas à internet, ocorreu uma especialização dos sistemas por função (cliente ou servidor) (Melo et al., 1998).

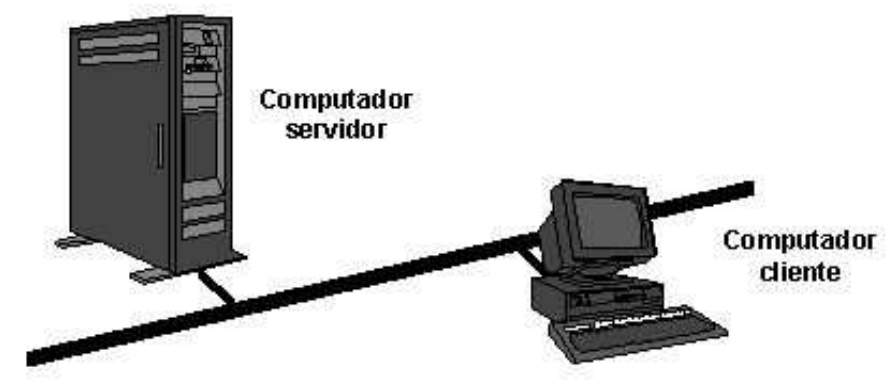

Figura 4 - Comunicação entre um computador servidor e um computador cliente (Silva \& Remoaldo, 1995)

1 O termo cliente será usado neste trabalho para se referir a um computador que solicita um serviço a um computador Servidor 
Um destes serviços disponíveis é o HTTP que é um dos grandes responsáveis pela popularização da internet e também é conhecido como WWW ou Web. $\mathrm{O}$ serviço $\mathrm{Web}$ implementa um sistema de hipertexto ${ }^{2}$ usado para navegação por documentos que possuem uma ligação (link) compondo uma teia de informações. Essa teia permite ao usuário navegar de uma página a outra clicando em um link. Cada documento da $W e b$, que é formado por um conjunto de páginas, é chamado de site. Cada página de um site possui um endereço exclusivo denominado Universal Resource Locator (URL).

De acordo com Itri (1999) a Web surgiu em 1989, no Laboratório de Pesquisas Nucleares da Suíça (CERN), quando um físico chamado Tim Bernes-Lee criou um mecanismo para que os cientistas pudessem compartilhar informações de texto de forma rápida, fácil e transparente pela internet.

Em 1993, Marc Andressen criou o navegador Mosaic, que possuía uma interface gráfica (ao invés da interface somente texto) e que incorporou novas características à $W e b$ como por exemplo a capacidade de incluir imagens em um documento. $\mathrm{O}$ autor do Mosaic fundou mais tarde a Netscape.

Em 1994, foi fundando o World Wide Web Consortium, conhecido pela sigla W3C, tendo Tim Berners-Lee como diretor, com a função de dar continuidade ao desenvolvimento da $\mathrm{Web}$ e de protocolos de padronização, bem como das especificações da própria linguagem HTML (W3c, 2004). A este consórcio, que era composto inicialmente pelo CERN e o Instituto de Tecnologia de Massachussets, juntaram-se centenas de universidades e companhias.

A $W e b$ é formada por três componentes principais: HTML, URLs e HTTP. O HTML é a linguagem de formatação utilizada para montar a visualização de um documento no navegador. URLs são endereços utilizados para buscar os documentos HTML em um servidor Web. HTTP é o protocolo de comunicação que especifica as regras para transferência dos conteúdos entre o servidor $W e b$ e os navegadores.

O servidor Web é um aplicativo responsável pelo controle de distribuição de páginas HTML em uma rede TCP/IP. Sua função é aguardar por requisições de páginas

${ }^{2}$ Hipertexto é uma metáfora para a apresentação de informações nas quais textos, imagens, sons e ações ficam interligados em uma teia complexa e não linear de associações que permite ao usuário percorrer assuntos interrelacionados independentemente da ordem em que os tópicos são apresentados 
de um navegador e, ao receber uma requisição, retornar dados ao cliente, no formato de paginas HTML. Ao receber os dados enviados pelo servidor como resposta de sua requisição, o navegador executa um processo chamado de renderização a partir do conteúdo da página e apresenta na tela os documentos formatados para o usuário.

O Apache é atualmente o servidor Web mais utilizado segundo a Netcraft (Netcraft, 2005) e tem como uma das principais vantagens o custo, pois é disponibilizado gratuitamente. O segundo servidor mais utilizado é o IIS (Internet Information Server) da Microsoft.

O Apache surgiu em 1995, a partir da evolução de um servidor Web chamado NCSA, com a contribuição de voluntários que criaram a Apache Software Foundation. Esse grupo tem sido responsável pelo desenvolvimento constante do software ao mantê-lo com o status de servidor $W e b$ mais utilizado no mundo. Grande parte desta popularidade do servidor Apache se deve ao fato de ser um software de código aberto, obtido gratuitamente, que permite implementar e adaptar novas características para atender necessidades próprias de cada projeto.

Uma outra característica importante do servidor Apache é a sua arquitetura modular, que aceita a inclusão de praticamente qualquer característica desejada em um servidor Web. A sua modularidade associada a um núcleo simples, faz com que ele seja bastante flexível e possa atender necessidades muito específicas de cada site.

\subsubsection{Páginas dinâmicas na Web}

A funcionalidade básica do servidor $W e b$ de retornar páginas estáticas escritas em HTML limita o servidor $W e b$ a apenas enviar uma página que foi previamente construída de volta pela internet para o navegador do usuário.

Para que fosse possível criar aplicações interessantes em um sistema pela Internet, diversas soluções foram desenvolvidas a fim de permitir o envio ao usuário de páginas personalizadas e que oferecem uma experiência de navegação mais dinâmica.

Essas soluções podem ser divididas em dois grupos: tecnologias do lado do computador cliente e tecnologia de processamento do lado do computador servidor (Castagnetto et al., 1999) . 
Nas tecnologias do lado do computador cliente o navegador do usuário é que executa uma determinada tarefa a fim de enriquecer as páginas HTML. São exemplos dessa tecnologia o ActiveX, os Applets Java e o Java Script.

Nas tecnologias do lado do servidor, o servidor Web é responsável por executar as tarefas e uma das primeiras soluções que surgiu foi o chamado Common Gateway Interface - CGI. Ele é a interface do servidor Web que é capaz de chamar um programa ou aplicação e capturar a resposta gerada para ser apresentada de volta ao usuário possibilitando a interação com o usuário na forma de páginas HTML.

De acordo com Castagnetto et al.(1999) o processamento e a geração de páginas $W e b$ do lado do servidor oferecem várias vantagens com relação às tecnologias de processamento do lado do cliente:

- Minimiza o tráfego de rede ao limitar a necessidade de navegador e servidor dialogarem constantemente entre sí;

- Reduz o tempo de carregamento, porque apenas o conteúdo da página é carregado pelo usuário;

- Evita problemas de compatibilidade entre navegadores;

- Pode propiciar dados que não estão no computador do usuário, e;

- Propicia medidas de segurança bem melhores, pois pode-se programar coisas que não serão transferidas para o computador do usuário (apenas o produto final é baixado) impossibilitando o acesso a dados que se deseja ocultar.

A aplicação CGI pode ser programada em praticamente qualquer linguagem, sendo mais usual encontrarmos aplicações escritas em $\mathrm{C} / \mathrm{C}++$, Microsoft Visual Basic, Borland Delphi, por serem linguagens bastante conhecidas.

A utilização do CGI propiciou uma forma de se criar um aplicativo Web que pudesse receber informações enviadas pelo usuário, consultar bancos de dados, realizar tarefas, e uma página HTML que fosse resultante destes processos. No entanto, a utilização do CGI não poupa recursos do servidor pois sempre que uma requisição é recebida pelo servidor $W e b$, um novo processo por inteiro é criado. Se ocorrerem várias solicitações simultâneas isto pode sobrecarregar o sistema.

Desta forma diversas soluções integradas aos servidores Web foram desenvolvidas para que se pudesse atender a múltiplas requisições sem ter que criar um 
processo para cada uma. Como exemplos destas soluções temos o PHP, o Active Server Pages (ASP) da Microsoft e os Servlets Java.

Estes sistemas são soluções do tipo Server Side Script onde, após o servidor receber uma requisição de uma página, ele primeiro a procura e então executa o código de script embutido nele. O resultado dessa execução é uma página HTML.

\subsection{Sistemas de divulgação de geoinformação via internet}

A disseminação de geoinformação via internet começou a partir da disponibilização de mapas estáticos, que eram cópias digitalizadas de produtos cartográficos originais transformadas em imagens digitais. Estes mapas no formato matricial eram pouco interativos para os usuários, e, devido ao tamanho que estes arquivos atingiam, sua transmissão pela $W e b$ era dificultada. $\mathrm{O}$ pouco de interatividade era conseguido colocando-se links para outras páginas em áreas específicas do mapa utilizando-se um recurso da linguagem HTML chamado mapa de imagem.

Esse cenário era muito diferente do que ocorria com aplicações de SIG que rodavam localmente na máquina do usuário (aplicação standalone). Nessas aplicações os dados espaciais são mantidos no mesmo computador ou na mesma rede local, de onde os dados são visualizados e consultados. Essa arquitetura permite a transferência de grandes quantidades de dados entre o banco de dados e o software. Já numa arquitetura onde se utiliza a internet para a transmissão desses dados geográficos entre um computador remoto e a máquina de um usuário, essa velocidade de transferência é menor, alterando o tempo de resposta da aplicação.

Desta forma, ocorreu uma evolução de tecnologias que possibilita a disseminação de informações geográficas de forma mais interativa, proporcionando uma experiência mais rica ao usuário.

Essas tecnologias que permitem a disseminação de mapas pela internet não são, entretanto, um sistema de SIG completo, pois geralmente implementam apenas a funcionalidade de visualização dos dados e análises simplificadas, sem as poderosas funções de análise que os SIG propriamente ditos possuem. Elas foram desenvolvidas tanto 
por empresas (Autodesk, Intergraph e ESRI, etc) que criaram produtos comerciais, como também por Instituições de Pesquisa, Universidades e comunidades de Software Livre.

Miranda (2003) classifica essas tecnologias em dois tipos: servidor de mapas na $W e b$ e visualizador de mapas.

No primeiro tipo, um servidor $W e b$ envia uma imagem com a representação do mapa para o navegador $W e b$ do usuário. Na interface do navegador, podem existir opções para o usuário interagir com o mapa como um botão de zoom ou um botão de deslocamento do quadrante de visualização. Se uma destas opções for selecionada, o navegador faz uma nova requisição para o servidor, que responde à solicitação com uma outra imagem. Um outro recurso para a interatividade, além destes botões, é o envio de uma solicitação ao servidor, quando o usuário executa o click em alguma área da imagem, juntamente com as coordenadas $\mathrm{X}$ e $\mathrm{Y}$ do ponto clicado e também o tipo de operação que o servidor deve executar (zoom in, zoom out, pan, etc).

Neste tipo de tecnologia a execução de todos os cálculos para criar a imagem com um quadrante do mapa é feita pelo servidor. O navegador $W e b$ do usuário apenas mostra esta imagem. O uso deste tipo de solução tem como vantagem a minimização da necessidade de recursos tanto, de hardware como de software, do usuário pois, segundo Miranda (2003) “... a vantagem das imagens matriciais está nos algoritmos simples para manipulá-las".

O segundo tipo de tecnologia, chamada de visualizador de mapas, é um aplicativo executado no computador do usuário, que acessa dados que são carregados pela internet de uma só vez, diferentemente do tipo de tecnologia anterior, que faz requisições sucessivas ao servidor. Utilizando esta tecnologia, também conhecida como "cliente de apresentação", ocorre a transmissão de todos os dados no formato vetorial para a máquina do usuário, que podem visualizá-los a partir de programas acoplados aos navegadores (plugins ou applets Java).

Esta solução permite uma maior flexibilidade do lado do computador cliente (usuário) pois as operações de visualização e consulta aos dados são feitas localmente. A transferência destes dados demanda um tempo inicial para que todas as informações sejam transferidas por completo no momento em que se inicia o programa. Estando todos os dados no computador cliente, como as operações realizadas posteriormente são feitas 
localmente, o tempo de resposta é baixo. Temos como exemplos de produtos desta categoria o Geomedia Web Map da Intergraph Corporation, o Map Guide da Autodesk e o SpringWeb do Instituto Nacional de Pesquisas Espaciais.

A utilização de servidores de mapas possibilita que usuários possam acessar um banco de dados espacial em uma máquina remota utilizando um navegador $W e b$ comum, sem que seja necessário o acoplamento de programas adicionais para as operações de visualização e consulta, pois os dados são transferidos na forma matricial.

Os servidores de mapas recebem requisições do navegador e enviam como resposta uma imagem de tamanho fixo. Os formatos de imagens utilizados neste método devem ser do tipo que possa ser compactado para que se obtenha uma boa performance destes sistemas. As imagens são obtidas por um processo de matricialização, que é a transformação de dados no formato vetorial para o formato matricial (Kleiner, 2000)

$\mathrm{Na}$ transmissão de arquivos matriciais a transmissão é feita em acessos sucessivos ao servidor. O usuário consegue visualizar apenas as imagens enviadas a cada requisição e qualquer novo pedido tem que ser enviado novamente para o servidor, resultando em mais uma transferência de dados pela rede. Portanto, a velocidade de acesso deve ser levada em conta quando se utiliza esta solução, pois, ao contrário da primeira, se houver problemas de velocidade de transmissão de dados pela rede isto pode resultar em longos e sucessivos tempos de resposta.

O uso de servidores de mapas tem como vantagem o fato de que não é necessário carregar, instalar ou manter qualquer software ou dados especiais na máquina do usuário. Ele permite diferentes tipos de acesso aos dados, principalmente em servidores com um banco de dados bem-organizado. A desvantagem é que a cada nova pesquisa, é gerado um novo mapa.

O servidor de mapas proprietário mais conhecido no Brasil é o ArcIMS da empresa americana ESRI. Esta solução de software é bastante vendida para os órgãos públicos brasileiros e custa cerca de US\$11.000,00 (Uchoa, 2005).

Além dos softwares proprietários existem diversos softwares livres, que podem ser utilizado gratuitamente como por exemplo o MapServer, o TerraLib/Java, o TerraLib/php e muitos outros aplicativos (Wagner, 2005). 
O MapServer é um ambiente de desenvolvimento de Código Aberto para a construção de aplicações espaciais em ambiente $W e b$. Ele é desenvolvido na liguagem $\mathrm{C} \mathrm{e}$ não é um SIG completo, mas sim uma solução de software que fornece as funcionalidades necessárias para suportar uma ampla variedade de aplicações Web espaciais. (Mapserver, 2005).

O MapServer é baseado em uma aplicação CGI que gera dinamicamente as imagens dos mapas via Web. Além desta aplicação principal, o pacote também contém outros aplicativos para construção de mapas, barras de escalas e legendas.

A seguir serão citados alguns trabalhos selecionados na literatura científica que tratam da utilização de servidores de mapas para interação com geoinformação.

Osses et al. (2000) desenvolveram uma aplicação cliente-servidor para a disseminação de dados geográficos na Internet no formato vetorial a partir de uma arquitetura de três camadas. A primeira camada consiste de um navegador Web que serve como um Cliente Universal. Acoplado ao navegador temos um applet JAVA que é responsável por funções ligadas ao cliente tais como a apresentação de mapas e objetos geográficos, controle de diálogos e interfaces, controle de cache de dados e controle de geração de expressões em linguagem de consulta. A segunda camada é constituída de um servidor para protocolos HTTP com capacidade de executar servlets em JAVA. O applet conecta-se a um servlet disponível utilizando o protocolo HTTP. A terceira camada é composta por um Sistema Gerenciador de Banco de Dados Relacional que armazena todos os dados utilizados pelo sistema.

Kleiner (2000), também utilizando o Geomedia Web Map, construiu um Atlas digital. O Geomedia Web Map pode disponibilizar os mapas no formato matricial (imagens) ou vetorial (utilizando um plug-in chamado Active CGM). No formato matricial o mapa disponibilizado é dinâmico e não interativo, isto é, permite navegar utilizando-se as funções de pan e zoom, mas não permite interagir com os objetos diretamente no mapa. Utilizando o Active CGM, o mapa que o usuário visualiza é dinâmico e interativo, mas é necessário fazer download do plug-in que funciona apenas nos navegadores Internet Explorer e Netscape. Neste caso, as operações para a visualização dos mapas são executadas localmente. $\mathrm{O}$ autor conclui neste trabalho que, com a tecnologia que foi utilizada, o acesso aos mapas na forma vetorial exige que a conexão seja de banda larga, 
além de estar limitado apenas a dois tipos de navegadores, restringindo desta forma a base de usuários que podem acessar o sistema.

Em Mangabeira et al. (2003), foi utilizado o software Mapserver para a disponibilização de imagens e mapas da cidade de Holambra para os pequenos produtores rurais. Segundo os autores a disponibilização dos dados via Web criou oportunidades de análise e identificação de problemas pela população de Holambra.

\subsection{Engenharia de Software}

Presman (2002) define Engenharia de Software com“...aplicação de uma abordagem sistemática, disciplinada e quantificável, para o desenvolvimento, operação e manutenção do software...". Ela existe para melhorar o processo de construção do software.

Segundo o mesmo autor, em um processo de desenvolvimento de software, o ponto de partida para o desenvolvimento é a escolha de um modelo de processo de software, pois este representa “...uma tentativa de trazer ordem para uma atividade inerentemente caótica".

O modelo mais antigo e mais utilizado é o modelo em cascata, onde o processo de desenvolvimento do software é dividido em subprocessos que são executados em uma sequiência ordenada (Sommerville, 2003). O modelo em cascata é constituído pelas atividades de análise, projeto, geração de código e testes (Figura 5).

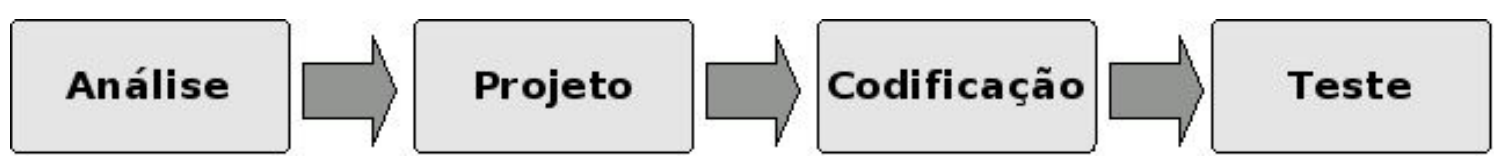

Figura 5 - Modelo em cascata de desenvolvimento de software (adaptado de Pressman, 2000)

A atividade de Análise constitui o processo de levantamento de requisitos do sistema onde se define qual a extensão do projeto, qual a quantidade de tempo e recursos necessários para sua execução. Esta atividade também tem como objetivo determinar os requisitos do software e documentá-los para a formalização do projeto de software. Para 
esta documentação pode-se utilizar a forma descritiva textual ou alguma linguagem gráfica como os diagramas IDEF0.

De acordo com IDEF (2005) o IDEF0 é um padrão de linguagem gráfica que provê um modelo de compreensão de atividades, relacionamentos funcionais e dados, que foi desenvolvido pela Força Aérea Estadunidense. Ele permite modelar processos em um modelo com uma representação hierárquica de suas etapas, que podem ser decompostas em diversos níveis.

O IDEF0 representa uma coleção de atividades e outras ações utilizando-se de setas e caixas chamados de "ICOMs" (Input, Control, Output, Mechanism - entrada, controle, saída e mecanismo). Cada atividade ou função é conceitualmente representada por uma caixa retangular, sendo que esta atividade pode ser decomposta em vários subníveis. Estes subníveis seguem as mesmas convenções. As linhas com setas não representam fluxo ou seqüência como num modelo de fluxo tradicional (fluxogramas). Elas indicam objetos ou dados que são utilizados pelas funções e de acordo com o lado que estão entrando na caixa, elas têm um significado. Setas entrando pelo lado esquerdo da caixa representam as entradas (informações, insumos, etc) da função. Setas entrando no lado de cima, representam os controles que especificam as condições de como a função deve gerar a saída correta. Setas deixando a caixa pelo lado direito indicam saídas que são as informações ou objetos produzidos pela função. Setas conectadas na parte inferior da caixa representam os mecanismos utilizados para a execução daquela função.

Na segunda atividade do ciclo de desenvolvimento do processo de software em cascata, que é o projeto, os requisitos do software são traduzidos num conjunto de representações que definem como este será desenvolvido. Aspectos como estrutura de dados, arquitetura, detalhes procedimentais (algoritmos) e caracterização de interfaces são definidos nesta etapa.

Nesta etapa também pode-se utilizar a linguagem de modelagem visual UML (Unified Modeling Language), proposta por Booch et al. (2000), que utiliza vários tipos de diagramas para auxiliar o projetista a documentar o projeto lógico do software, utilizando o conceito de orientação a objetos para sua construção. 
A orientação a objeto é um paradigma para a construção de softwares onde os objetos do mundo real são abstraídos como classes de código, compondo assim os blocos de construção do software (Winblad et al., 1990).

A utilização de conceitos de orientação a objetos é útil pois implementa conceitos como a abstração, o encapsulamento e a herança. Uma classe é um modelo de um objeto que inclui propriedades e métodos que descrevem esse objeto e o que ele é capaz de fazer. Se o objeto do mundo real for por exemplo um telefone, ao abstraí-lo como uma classe, as propriedades serão informações a respeito de suas características (como por exemplo: largura e comprimento, para se possa determinar com o o telefone interage com outros objetos físicos ao seu redor) e os métodos utilizam o valor dessas propriedades para realizar alguma tarefa (Castagnetto et al., 1999).

Um objeto é constituído por um conjunto de atributos e um conjunto de métodos. Os atributos definem as características do objeto e os métodos definem o comportamento do objeto. As características dos objetos somente são acessadas através dos métodos e desse modo ocorre um encapsulamento dos detalhes de implementação do objeto. Objetos com características e comportamento semelhantes são agrupados em classes.

Um outro aspecto no desenvolvimento de software que se considera na etapa de projeto é a modelagem do banco de dados, onde tem-se o modelo relacional como o mais utilizado (Melo et al., 1998).

O Modelo Relacional usa um conjunto de tabelas para representar tanto os dados como as relações entre eles. Uma linha em uma tabela representa um relacionamento entre um conjunto de valores. Uma vez que essa tabela é um conjunto de relacionamentos, há uma estreita correspondência entre o conceito de tabela e conceito matemático de relação. Foi desta correspondência que surgiu o nome do Modelo Relacional. A descrição completa do Modelo Relacional pode ser encontrada em Codd (1990).

Na fase seguinte do modelo em cascata, aparecem as etapas de Codificação e Teste.

Na etapa de Codificação, com base nas especificações do projeto que foram executadas na fase anterior, são criados os programas, que são a construção das intruções em uma linguagem de programação e a criação do banco de de dados. Na etapa de testes 
tem-se a depuração dos erros e a análise dos aspectos funcionais do sistema para garantir que o software irá produzir os resultados esperados. 


\section{METODOLOGIA}

\subsection{Introdução}

O sistema desenvolvido neste trabalho utilizou a filosofia de código aberto (open source) que aplica a licença GPL - General Public License, possibilitando que qualquer usuário tenha acesso ao código fonte do programa. As especificações desta licença podem ser encontradas no site ${ }^{3}$ da Open Source Initiative e também no código fonte do software.

Para o desenvolvimento deste trabalho foi utilizado o modelo de ciclo de desenvolvimento em cascata.

Inicialmente, na etapa de Análise, foram descritos os requisitos do software para poder levantar as necessidades do sistema. Além da descrição dos requisitos nesta primeira fase, também foram utilizados como ferramenta para a modelagem dos processos de negócios do sistema os diagramas IDEF0 - Integration Definition for Function Modelling.

Em seguida, na etapa Projeto, foi utilizada a técnica de orientação a objetos para se construir um modelo lógico do software que satisfaça os requisitos levantados. Também foi elaborada a arquitetura física do software. A base de dados foi modelada em um diagrama Entidade-Relacionamento, obtido a partir dos requisitos descritos.

As etapas de Codificação e Teste são discutidas no capítulo 4.

3 http://www.opensource.org 


\subsection{Análise}

\subsubsection{Requistos de usuários e informações}

Os dados provenientes das atividades de campo e as geoinformações oriundas das análises de especialistas convergem em um mesmo sistema. No esquema da figura 6 são representados o sistema computacional na parte central e as duas categorias de usuários para o qual o sistema foi modelado com os exemplos de dados com que cada um deles pode contribuir.

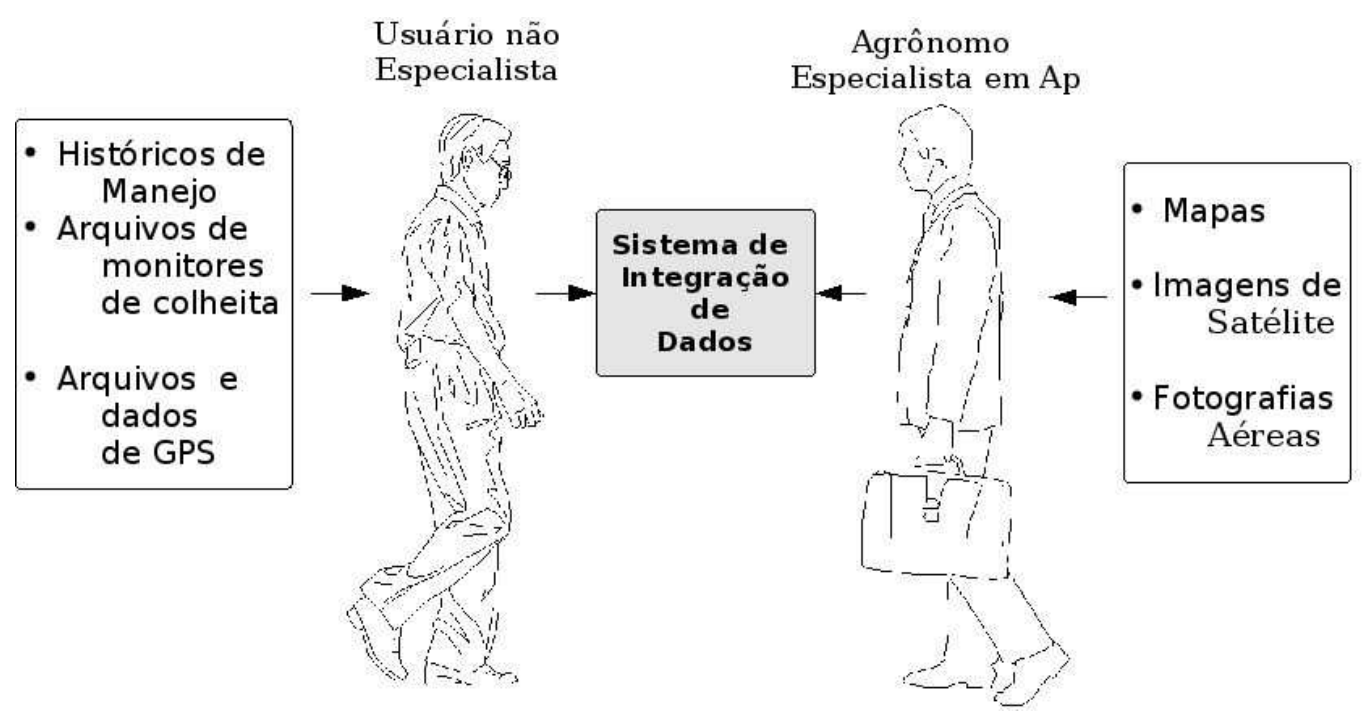

Figura 6 - Usuários e informações do sistema proposto

Do lado esquerdo são vistos os usuários não especialistas, que contribuem com dados de manejo executados nos talhões da fazenda, como a informação de uma operação de manejo ou de plantio de uma nova cultura. Também podem ser inseridas informações contidas em arquivos que podem estar em qualquer formato.

Do outro lado são observados os usuários especialistas, que têm capacitação técnica e utilizam softwares aplicados a AP. Eles contribuem com geoinformações na forma de mapas e imagens, que são produtos de análises com o uso de SIG genéricos ou dedicados à AP. 
A figura 7 oferece uma ilustração das ações que cada um dos usuários executa nesse processo. Os usuários que trabalham na fazenda e não são especialistas em AP acessam o sistema via internet. Após a autenticação do usuário, é disponibilizado a ele um mapa interativo, no qual ele pode executar duas operações: visualizar mapas diversos ou selecionar um talhão específico da fazenda e inserir informações sobre uma operação de manejo que foi realizada nesse talhão.

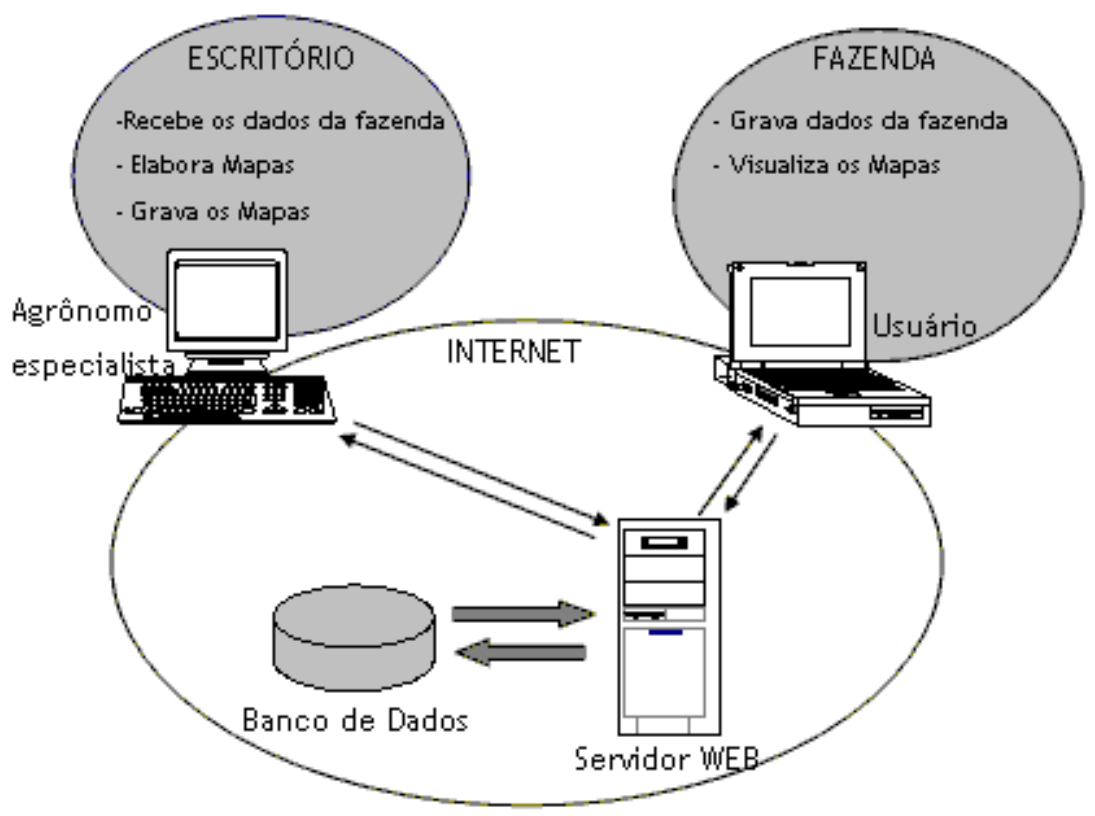

Figura 7 - Ações que cada tipo de usuário executa

Além destas informações, que neste trabalho são chamadas de histórico do talhão, estes usuários também têm a possibilidade de inserir arquivos de dados que podem ser provenientes dos monitores de produtividade ou de aparelhos de GPS. Os dados e arquivos são então armazenados no banco de dados remoto.

Este ambiente, onde existem as informações com históricos de manejo de uma fazenda e arquivos diversos, provê a todos os profissionais que estão relacionados com a atividade de agricultura da fazenda, um banco de dados único e centralizado com informações que muitas vezes não estão registradas em outros locais ou, se estão, encontram-se pulverizadas em diversas fontes de dados. Com esse sistema, é possível 
saber qual o histórico de determinado talhão de produção de forma rápida, fácil e remota apenas consultando os dados pela internet

\subsubsection{Requisitos de dados}

\subsubsection{Mapas e imagens}

O sistema proposto neste trabalho requer a capacidade para manipulação de documentos cartográficos, imagens de satélite e fotografias aéreas que vão compor a porção que trata de dados geográficos da base de dados. Todos estes elementos devem estar georreferenciados de forma que possam ser visualizados em um mesmo plano de referência e, desta forma, combinados em diversas camadas de visualização.

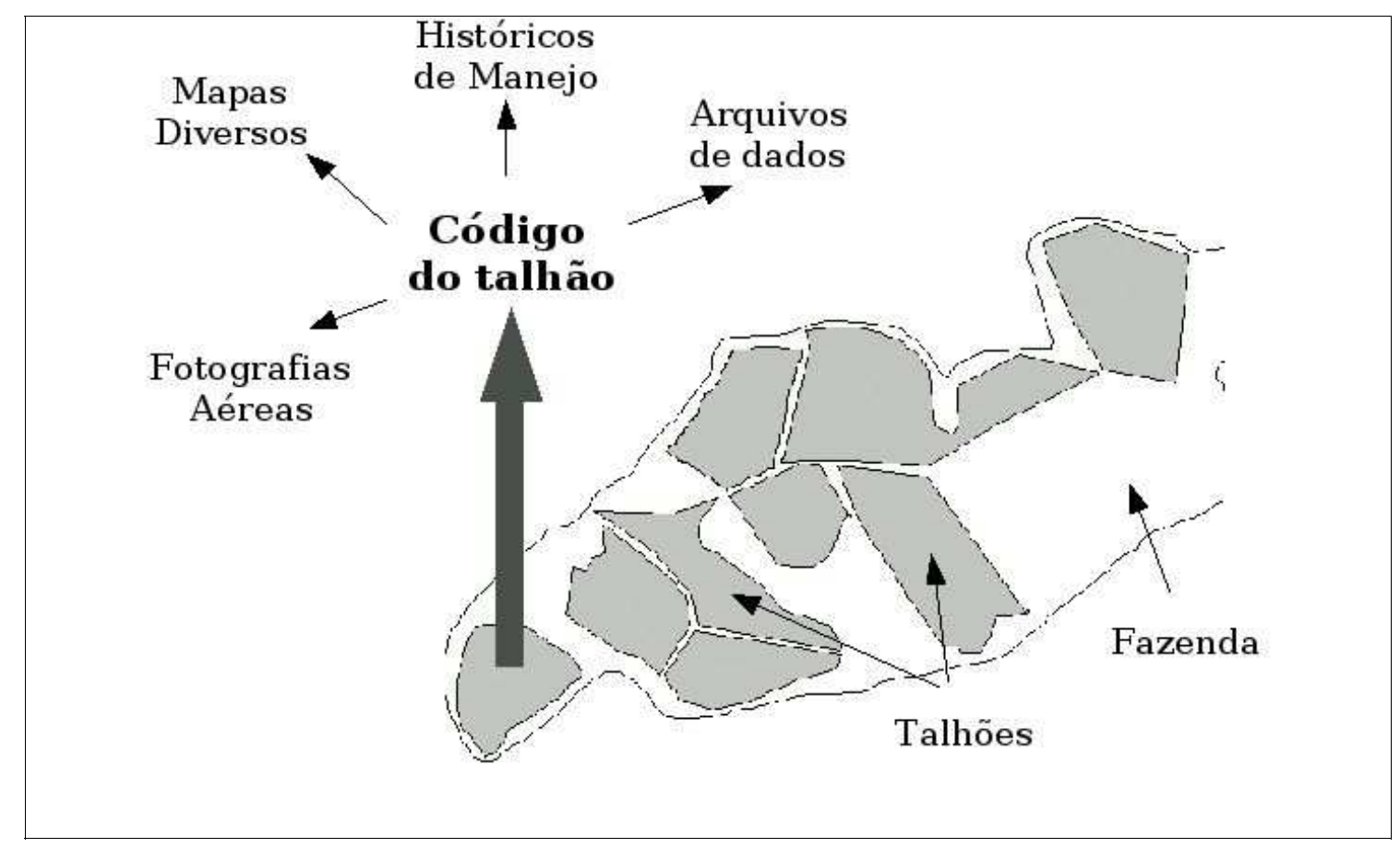

Figura 8 - Indexação de informações diversas ao geoobjeto talhão

Um elemento importante que deverá fazer parte deste conjunto são os mapas cadastrais. Tais mapas geralmente estarão no formato vetorial, contendo informações com o contorno da fazenda, hidrografia, topografia, etc. 
Dentre estes mapas cadastrais, os mapas que delimitam os talhões tem fundamental importância para este sistema pois os talhões serão os geoobjetos aos quais serão indexados os históricos e diversos outros mapas e arquivos.

Além do mapa propriamente dito, também serão necessárias as informações que o descrevem como sua legenda e título. Estes serão chamados de "metadados", isto é, são informações que descrevem estes elementos.

\subsubsection{Dados históricos do talhão}

Referem-se a operações de manejo que são executados em um talhão, como uma operação de gradagem, plantio, aplicação de insumos, etc. Esses dados compõem o histórico de tudo que foi feito naquela área de produção. Para gravar estes dados no banco de dados é necessário que se disponha de campos em tabelas para a inserção das informações da data, da descrição do histórico e das observações do usuário.

Um exemplo de dado histórico do talhão é a execução da aplicação de um determinado insumo em um talhão. Desta forma serão gravadas as seguintes informações no banco de dados:

- a data na qual foi executada a operação;

- a descrição da operação (ex: aplicação de determinado insumo);

- as observações que complementam as informações da operação (ex: tipo de produto, dosagem do produto, etc).

\subsubsection{Arquivos de dados diversos}

Ao final de uma jornada diária de colheita com a utilização de máquina colhedora provida de sistema monitor de colheita, os dados gerados por este aparelho ficam disponíveis em dispositivos de armazenamento (ex: disquetes, memória FLASH, cartões tipo PCMCIA, etc.) para que um usuário possa inserir estes dados em um software aplicado à AP. Nesses arquivos estão contidos dados como latitude, longitude, umidade do grão, fluxo de massa, largura de plataforma, etc. 
Os arquivos podem ser armazenados no ambiente proposto neste trabalho e, desta forma, constituem um requisito de dados para o sistema. Este requisito é composto pelos seguintes dados: data da colheita, tipo de monitor de colheita utilizado, talhão no qual foi realizada a colheita e outras observações.

Além dos dados oriundos de monitores de colheita, diversos outros fenômenos que ocorrem na área de plantio também são de interesse da $\mathrm{AP}$, pois de alguma forma influenciam no cultivo da lavoura. Muitos destes fenômenos possuem algum tipo de distribuição espacial que são interessantes de serem registrados com um GPS para posterior análise em um mapa. A delimitação de áreas infestadas por pragas e doenças, por exemplo, podem ser mapeadas com o auxílio de um GPS para o estudo de estratégia de manejo em relação à contenção da praga ou doença. O levantamento é feito com o GPS capturando as coordenadas em modo dinâmico à medida que o operador percorre o limite das áreas infestadas. Como resultado desta atividade são definidas coordenadas geográficas que identificam um polígono que circunscreve a área infestada.

As coordenadas podem ser exportadas do equipamento GPS de duas formas: em arquivos que são obtidos através da conexão do equipamento em um microcomputador ou pela cópia manual destas coordenadas a partir do display do equipamento.

Além deste tipo de mapeamento existem outras atividades nas quais os GPS permitem mapear um fenômeno que ocorre na área de produção: a extração de amostras de solo para análises laboratoriais de características físicas, químicas e biológicas, abertura de trincheiras para levantamentos pedológicos, dados de levantamentos de altimetria, e outros. Neste caso os dados não são gravados de forma dinâmica do GPS pois representam pontos e não alguma linha limítrofe. Eles podem ser extraídos do aparelho de forma manual ou com o auxílio de um software em um computador.

Outros arquivos que representam alguma informação a respeito do talhão também podem compor a base de dados: fotografias comuns, planilhas eletrônicas, etc.

Todos estes arquivos compõem um requisito de dados para o sistema, que deverá possuir os seguintes campos para gravação dos dados:

- a data na qual foi coletada a informação; 
- a descrição da informação (ex: arquivo de monitor de colheita, arquivo de GPS, fotografia, etc);

- as observações complementares.

\subsubsection{Requisitos de interface do usuário}

A interface com o usuário tem um papel fundamental nos sistemas atuais que utilizam interfaces gráficas. Desde o surgimento dos sistemas baseados em janelas e ícones, as interfaces com o usuário dos sistemas modernos evoluíram oferecendo novas facilidades na interação do usuário com o sistema. A interface gráfica que é comumente utilizada nos computadores atuais evoluiu a partir do trabalho realizado nos anos 70 no Xerox Palo Alto Research Center e é chamada de interface gráfica do usuário - GUI (Graphical User Interface)(Winblad et al., 1990). Estas facilidades da interface são as características que muitas vezes determinam a escolha e preferência do usuário para a utilização de um software, e devem ser discutidas na fase de análise de requisitos.

De acordo com Schimiguel \& Baranauskas (2002) a interface deve ser concebida de forma que o usuário possa atingir seus objetivos facilmente, com pouca ocorrência de erros e com um nível de complexidade limitada à própria tarefa.

Esta interface deve levar em conta a velocidade da transferência de dados entre um navegador e um servidor $W e b$, pois se esta for muito baixa, como por exemplo em uma conexão discada com modem, pode ocorrer que esta comunicação demore em demasia, fazendo com que o processo de interatividade com figuras de mapas seja precário.

Um outro fator preponderante para esta discussão de requisitos de interface, é o perfil do usuário que utilizará o sistema. Muitas vezes o usuário possui poucas habilidades na manipulação de recursos informáticos, fazendo com que a existência de muitos botões de controles do software causem um efeito negativo na interação do usuário com os dados.

Desta forma, é necessário que se crie uma interface onde se possa navegar facilmente pelos dados e imagens, como por exemplo os mapas de variabilidade espacial da produtividade ou fotografias aéreas da fazenda. 
Para um sistema de interação com geoinformação via internet o item "a" é de grande importância pois a geração das imagens dos mapas deve ser feita em dimensão adequada, não só ao tamanho da área disponível no navegador, mas também à resolução utilizada pela saída de vídeo no computador do usuário. Neste caso, o desenvolvimento do layout da interface com uma resolução de vídeo de 800 por 600 pontos é recomendável pois desta forma não se restringe a base de usuário. Também deve se levar em conta que outros elementos como botões de navegação e informações sobre os mapas serão inseridos na página, além do mapa.

A interface também deverá implementar funcionalidades que tornem os mapas interativos e dinâmicos. Para que seja interativa, a interface deve ser capaz de reconhecer a seleção de um objeto no mapa bem como trabalhar com camadas (layers) de informação que poderão ser selecionados em uma visualização. Para que seja dinâmica, também é necessário que a interface permita que o usuário ajuste a escala na qual os mapas são visualizados, bem como sua posição no plano de referência. Estas capacidades são na verdade as ferramentas de navegação, que possuem a funcionalidade de deslocar a visualização do mapa em qualquer direção (pan) e possibilitam a ampliação do dados visualizados neste mapa (zoom).

Existem também outras informações, não geográficas e sim cadastrais (históricos do talhão e arquivos) e estão indexadas a objetos destes mapas. Como neste trabalho o objeto geográfico ao qual serão indexadas essas informações é o talhão, deve ser implementada uma forma que possibilite ao usuário selecionar um talhão específico para visualizar as informações indexadas a ele.

\subsubsection{Requisitos de acesso e segurança}

A construção de sistemas voltados à troca de informação via internet deve considerar a segurança como item de requisitos. Alguns destes requisitos são a utilização de um esquema de autenticação de usuários e de restrição de acesso a dados e a ações de acordo com o perfil do usuário. 


\subsubsection{Requisitos de comunicação}

A comunicação entre o navegador do usuário e o servidor Web deverá ser implementada utilizando o protocolo HTTP. São utilizados arquivos no formato matricial (imagens), manipuláveis por qualquer tipo de navegador sem que haja necessidade de instalação de plug-ins adicionais.

Isto implica que o tamanho das imagens geradas no processo de matricialização no servidor não podem ser muito grandes, visto que o uso do sistema deve ser estendido para qualquer tipo de conexão com a internet, independente de sua velocidade.

\subsubsection{Diagrama IDEF0}

A partir da análise de requisitos, foi elaborado o diagrama IDEF0, que oferece uma visão formalizada dos processos de negócio envolvidos no projeto (Figura 9).

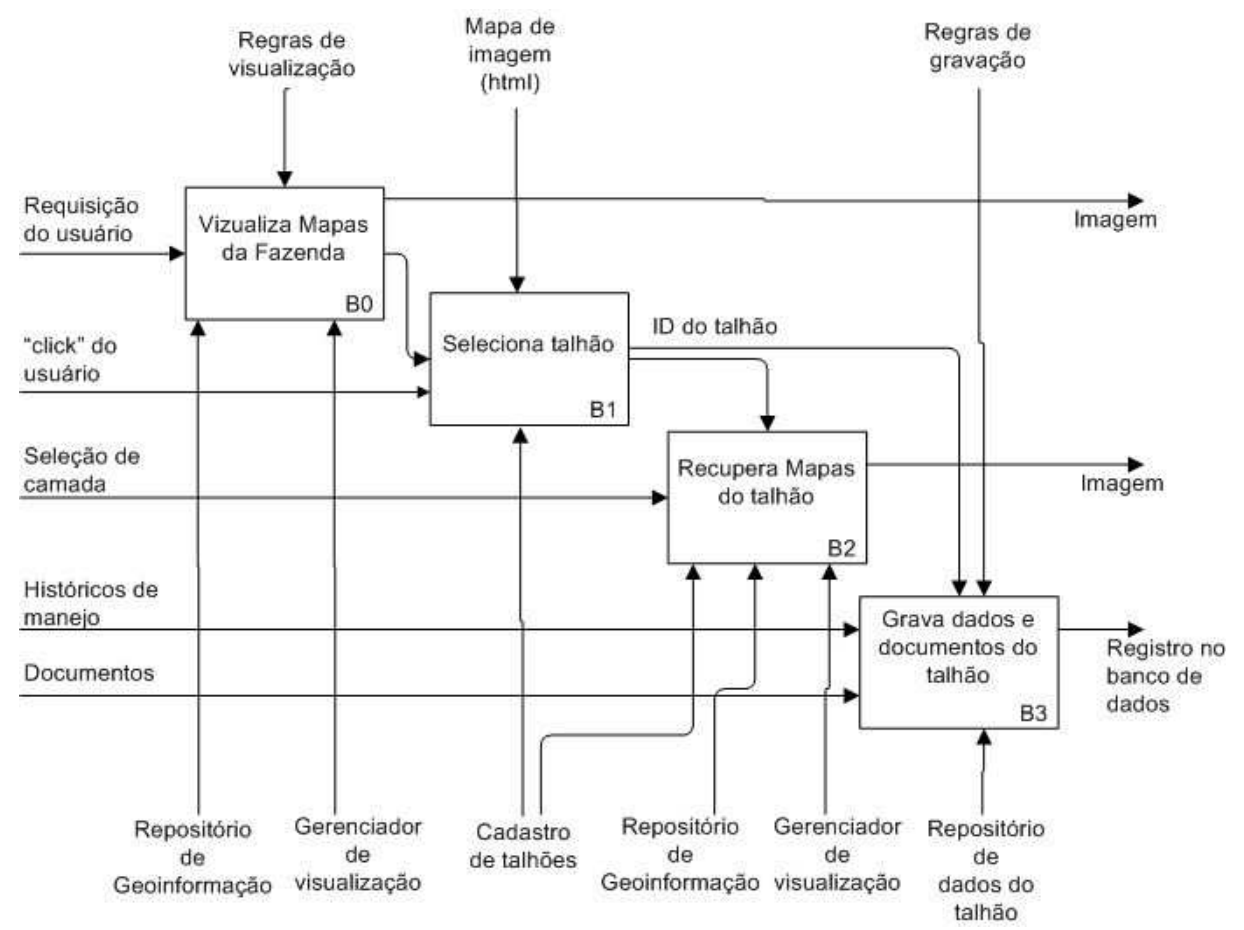

Figura 9 - Diagrama IDEF0 nível 2 


\subsection{Projeto}

A solução de software proposta é uma aplicação que implementa os requisitos expostos. A figura 10 contém um diagrama que ilustra sua arquitetura, que é composta por dois módulos: o módulo de aplicação e o módulo de banco de dados.

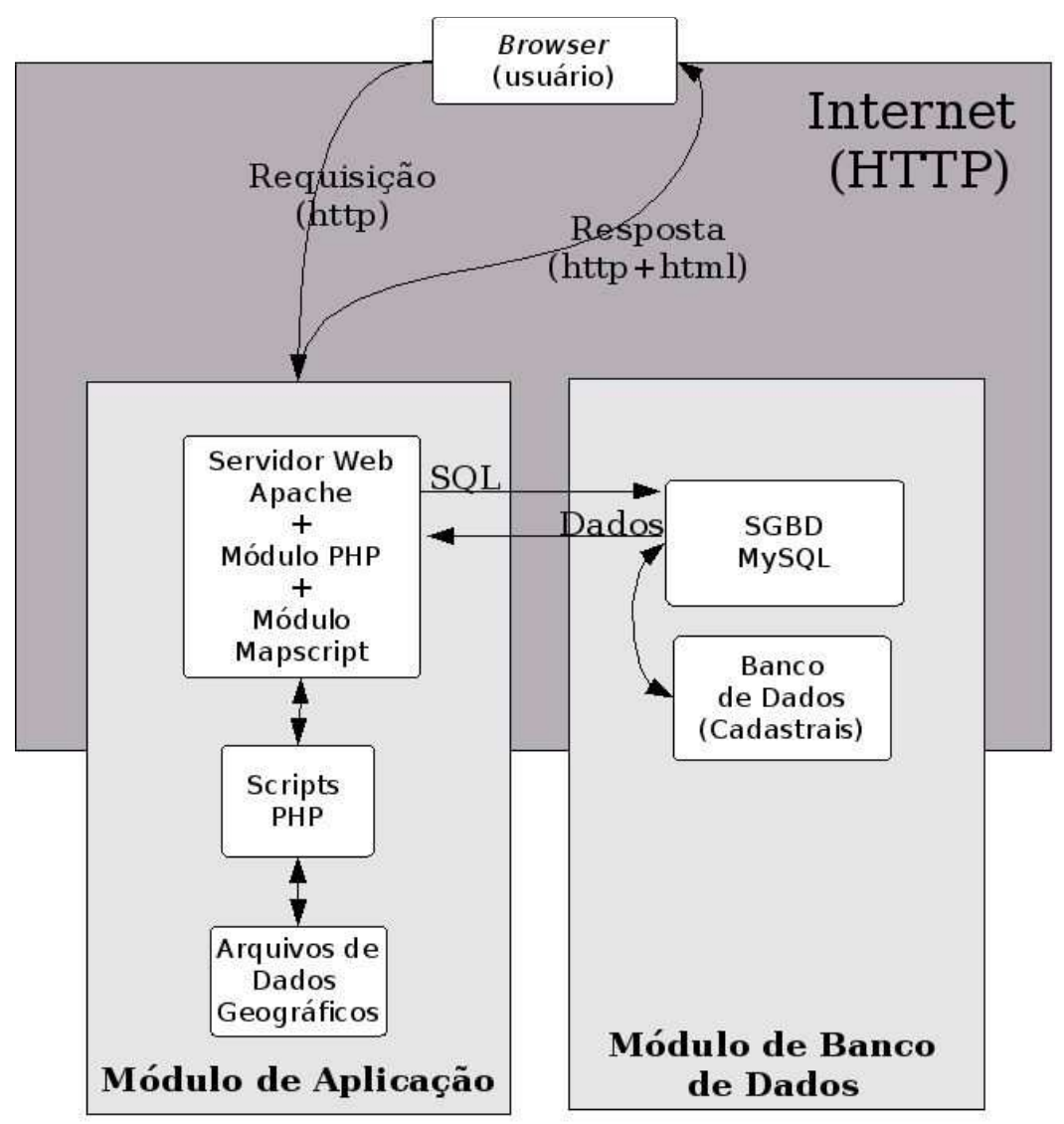

Figura 10 - Arquitetura física do Sistema

Estes módulos de software contém, respectivamente, os servidores de Web e o servidor de Banco de Dados, que trocam mensagens entre si. Os dois servidores podem ser executados em uma mesma máquina ou podem ser executados em máquinas diferentes, desde que estas estejam conectadas a uma rede TCP/IP.

O módulo de aplicação é a infra-estrutura composta pelos elementos Servidor Web Apache, o módulo PHP do Apache, o módulo Mapscript do Apache e o Scripts PHP. Este módulo de software é responsável pela realização das tarefas de 
controle dos dados que serão consultados e gravados no Servidor de Banco de Dados bem como da geração de mapas que serão visualizados pelo usuário.

Os arquivos vetoriais e matriciais contendo os diversos mapas e fotografias aéreas não são armazenados diretamente no banco de dados e sim em na estrutura de diretório do sistema de arquivos do servidor $W e b$, compondo uma arquitetura dual. A organização destes arquivos é feita em uma estrutura hierárquica de diretórios organizados por projeto. As informações dos atributos, metadados e localização destes arquivos na estrutura de diretórios são gravadas no banco de dados.

O software utilizado como servidor $W e b$, que é a parte principal do módulo de aplicação, é o Apache. Além de distribuir páginas em HTML a partir da requisição do computador cliente, este servidor $W e b$ também pode ter a sua funcionalidade estendida através de módulos. Estes módulos são componentes de software que adicionam funcionalidade para o servidor. Os módulos que serão utilizados são o interpretador de PHP e o manipulador de dados geográficos Mapscript.

A linguagem PHP é muito similar à linguagem $\mathrm{C}$ e permite programação estruturada e orientada a objetos. Os scripts PHP são incorporados dentro de uma página HTML e são executados no servidor antes que a página seja enviada ao navegador. $\mathrm{O}$ PHP é gratuito e seu código é aberto.

Ainda analisando o módulo de aplicação, temos o Mapscript, que consiste em um módulo do servidor web Apache que pemite a leitura de arquivos contendo dados geográficos.

O Mapscript é um projeto derivado do Mapserver que é um software livre que disponibiliza um ambiente de desenvolvimento para construção de aplicações geospaciais na internet, possibilitando a leitura dos arquivos vetoriais e matriciais e a sua conversão em figuras que serão visualizadas pelo navegador do usuário. Para criar esta imagem que corresponde à visualização do mapa, o gerenciador de visualização faz a chamada para a função do mapscript para criação de uma visualização informando os argumentos que determinam as coordenadas da visualização e as camadas que serão visualizadas.

Os arquivos vetoriais, que vão compor a base de dados que contém a geometria dos dados, são arquivos do tipo ESRI shapefile, que é um formato de 
armazenamento de informações geográficas na forma de vetores. Eles são amplamente utilizados em sistemas que tratam de dados geográficos e isso faz com que a maioria dos softwares aplicados a AP e softwares genéricos de SIG possam exportar arquivos neste formato. As fotografias aéreas e imagens de satélite têm o formato do tipo TIFF que suporta o georreferenciamento da imagem.

O Mapscript transforma arquivos no formato ESRI shapefile e TIFF em imagens do tipo PNG. Ele também possibilita a sobreposição dos arquivos vetoriais e matriciais, possibilitando a composição de camadas de visualização (layers) pelo usuário.

O formato shapefile é o padrão utilizado pelos produtos ESRI, como o ArcView. Os dados contidos nestes arquivos descrevem a geometria e atributos de entidades como pontos, linhas e polígonos.

Para a implementação da solução de software proposta neste trabalho que utiliza a Web como interface, fez-se necessário a escolha de um banco de dados que permitisse explorar as características básicas para implementação de uma aplicação cliente-servidor.

O MySQL é um gerenciador de banco de dados relacional, implementado nas liguagens $\mathrm{C}$ e $\mathrm{C}++$, que utiliza o $\mathrm{SQL}$ como forma de acesso e na manipulação dos dados armazenados. O MySQL é um software de código aberto e é distribuído gratuitamente.

\subsubsection{Estrutura e funcionamento do sistema}

A implementação do sistema consiste no desenvolvimento dos scripts que são interpretados pelo servidor $W e b$ e gerenciarão todas as informações do sistema. Consiste também na modelagem do banco de dados relacional, para que suporte as operações de armazenamento dos dados.

No contexto da Engenharia de Software, um modelo é uma representação abstrata dos elementos envolvidos na construção de um sistema. Esse modelo fornece uma infra-estrutura por intermédio da qual elementos e seus relacionamentos podem ser representados, definidos e analisados. 


\subsubsection{Modelagem do banco de dados}

Para a implementação da base de dados deste projeto de software foi realizada uma listagem das categorias de dados que serão armazenadas no sistema.

O sistema está estruturado para o armazenamento de uma coleção de dados que foram classificados em 5 grupos:

1) Dados de manejo, que compõem o histórico do talhão.

2) Arquivos em diversos formatos indexados aos talhões. Aqui estão incluídos os dados oriundos dos dispositivos monitores de colheita, dos GPSs para mapeamentos diversos nos talhões.

3) Mapas e imagens da propriedade. Compreendem todos mapas vetoriais que contém, por exemplo, a demarcação do limite da propriedade, a rede hidrográfica da propriedade, dados cadastrais de galpões e outras construções, mapas delimitando classes de dados como mata, pedologia, etc. Também compreendem as imagens matriciais (raster) como imagens de satélite, fotografias aéreas, imagens de sombreamento, etc.

4) Mapas indexadas a talhões. São essencialmente dados que se referem somente a um talhão específico e, por questões de organização dos dados e visualização destes, são indexados aos talhões. São mapas vetoriais contendo dados como unidades de gerenciamento, isolinhas de produtividade da área, produtividade por células, etc.

5) Detalhes de cada projeto, como as coordernadas do retângulo envolvente, o nome do projeto, os usuários que podem acessá-lo, etc.

Além destas informações, também existem outras que se referem ao funcionamento do sistema, como o cadastro de usuário, dados, sessão, etc.

A partir desta breve descrição dos dados é possível identificar as entidades que comporão o modelo E-R do banco de dados.

O diagrama do modelo é apresentado na figura 11. 


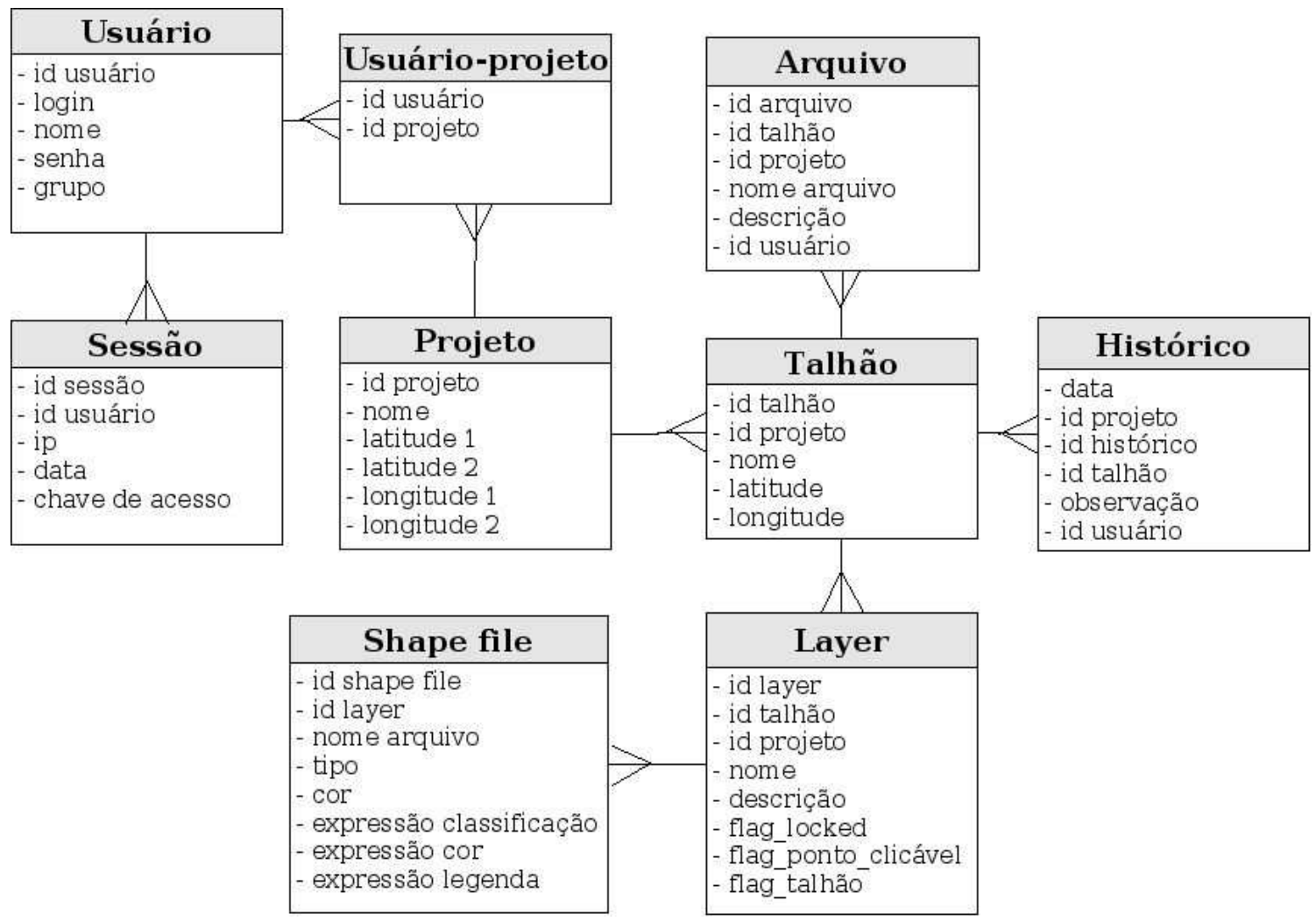

Figura 11 - Modelo Entidade-Relacionamento do banco de dados

\subsubsection{Modelagem do Sistema}

O modelo de Classes do sistema é composto por 8 classes que foram agrupadas em 3 módulos lógicos(Figura 12): módulo Sistema, módulo Mapas e módulo Dados. 


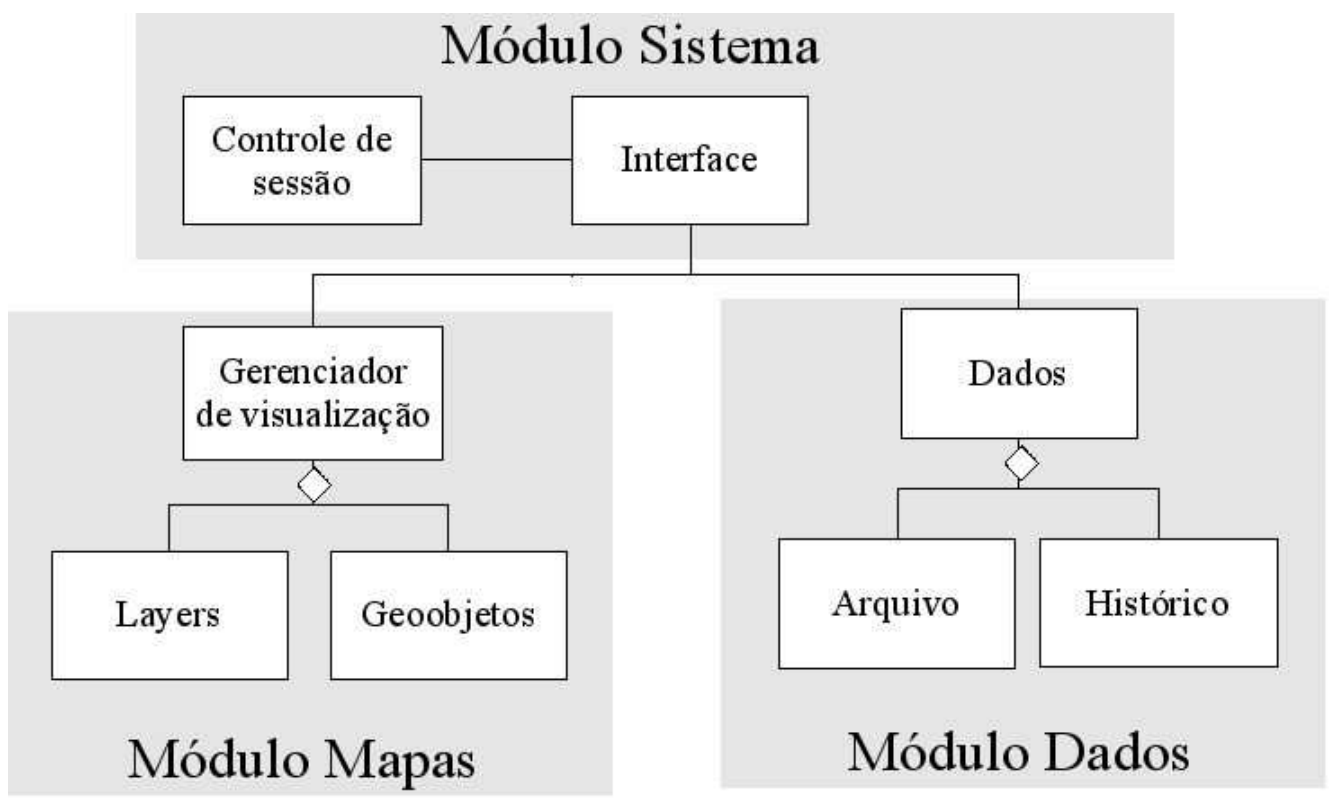

Figura 12 - Diagrama de Classe do modelo UML

\subsubsection{Módulo lógico Sistema}

O módulo Sistema implementa os requisitos de segurança de controle de acesso a dados e de gerenciamento de sessão e login. Também é responsável pela montagem da página em HTML que será transmitida ao usuário.

A classe Interface é quem faz o controle do menu de funções que cada um dos usuários tem acesso. Este menu de funções foi estruturado em dois conjuntos, cada um voltado para uma categoria de usuário do sistema, de forma a facilitar a navegação.

As funções de inclusão e alteração de dados são executadas através de formulários HTML que recebem os dados e a requisição do usuário para ser processada no servidor.

A classe Controle de Sessão implementa a autenticação do usuário e o controle de sessão. Esta autenticação é feita a cada acesso ao servidor, mas exige que o usuário insira seu login e senha no sistema uma única vez durante o login. Para que as autenticações consecutivas possam acontecer são utilizadas chaves de sessão que são passadas pelo usuário e checadas pelo servidor a cada requisição de página. 


\subsubsection{Módulo lógico Mapas}

O módulo Mapas é responsável pela geração da visualização dos mapas bem como do controle das camadas que são sobrepostas para gerar as imagens que serão visualizadas pelo navegador. Para isso, existe no banco de dados uma tabela onde estão relacionados os arquivos (Shapefile ou TIFF) e seus rótulos que compõem cada uma das camadas de visualização. Uma camada de visualização pode possuir mais de um arquivo relacionado a ela, de modo a compor um layer.

Também é neste módulo que são criados os pontos clicáveis dos objetos da visualização. A classe Geoobjetos cria os pontos clicáveis dos objetos através do recurso da linguagem HTML chamada de Mapa de Imagem que nada mais é do que definir uma ou mais áreas de uma figura que terão seu próprio link.

Inicialmente, para que esse mapa de imagem possa funcionar, é necessário que se faça a transposição das coordenadas geográficas dos objetos para a coordenada do plano da imagem. Esta transposição tem que levar em conta também a movimentação que é feita na visualização tanto em relação a deslocamentos horizontais e verticais(pan) bem como em relação aos efeitos de aproximação (zoom in) e distanciamento (zoom $o u t)$. Isso é feito utilizando-se a eq. (1).

$$
X_{i}=\frac{\left(X-X_{m}-D\right)}{R} * Z
$$

onde:

$X_{i}$ é o valor do eixo $\mathrm{X}$ no plano da imagem gerada

$X$ é o valor de longitude do ponto em UTM

$D$ é o deslocamento da longitude do ponto em UTM

$X_{m}$ é o menor valor de longitude do plano de informação em UTM

$R$ é o fator de relação entre a extensão da longitude do plano de informação pelo tamanho da figura gerada

$Z$ é o fator de Zoom que é obtido pela relação da extensão da longitude do plano de informação pela extensão da longitude da visualização atual 


\subsubsection{Módulo lógico Dados}

O módulo Dados faz o controle e gerenciamento das informações cadastrais que estão indexadas aos talhão. Essas informações são os históricos de talhão e também os arquivos indexados a este talhão.

\subsection{Softwares utilizados}

Toda a modelagem do sistema bem como a construção do código fonte e sistema operacional foi feita utilizando softwares livres.

Os modelos (diagrama IDEF0, diagrama de classe e diagrama entidaderelacionamento do banco de dados) foram construídos utilizando o software Impress da suíte Open Office, que é um sistema semelhante ao Power Point da Microsoft.

O servidor web Apache (módulo de Aplicação da arquitetura física) e o servidor de banco de dados Mysql (módulo de Banco de Dados) foram instalados no sistema operacional GNU/Linux (distruibuição Slackware, versão 10).

Toda a construção dos scripts PHP foi feita utilizando o editor de texto livre Vim. 


\section{RESULTADOS E DISCUSSÃO}

A implementação do projeto teve como resultados o código fonte do sistema e os comandos SQL para criação do banco de dados que podem ser acessados pelo endereço na internet: http://geocities.yahoo.com.br/wlady6. O código fonte é constituído por 27 arquivos de script PHP, que totalizam 2696 linhas.

Para a ilustração do uso do ambiente desenvolvido neste trabalho, será simulada uma operação dos dois tipos de usuários que compõem o sistema. Primeiro serão visualizadas as telas para os usuários não especialistas e depois para os usuários especialistas.

\subsection{Exemplos de uso de um usuário não especialista}

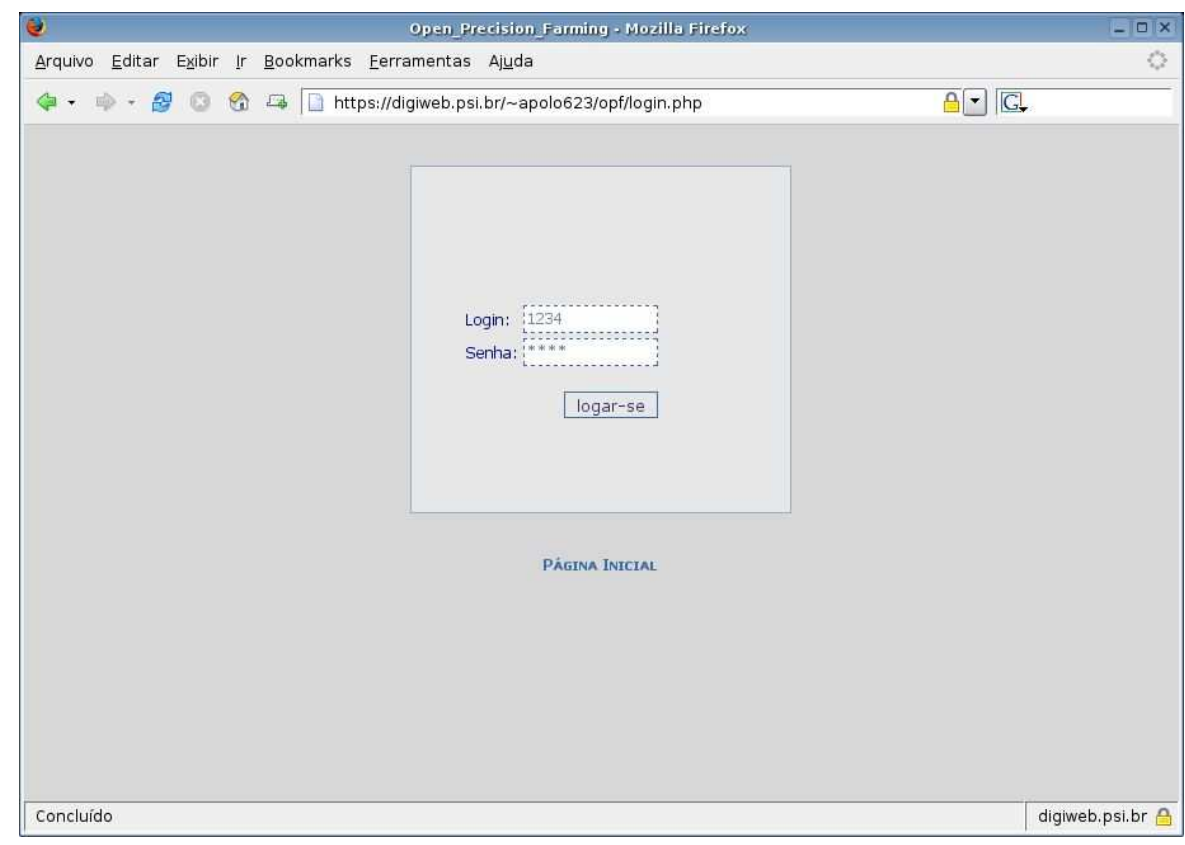

Figura 13 - Tela de autenticação de usuário 
Inicialmente o usuário acessa o site da internet onde está o sistema utilizando a endereço da máquina servidora. A tela de login é o primeiro passo para o acesso ao sistema onde o usuário será autenticado com o seu login e senha. Os dados que serão informados pelo usuário estão gravados em uma tabela no banco de dados para que seja possível certificar-se da identidade do usuário.

A figura 13 ilustra a tela de login. Após a autenticação do usuário, o sistema identifica os projeto aos quais este usuário está cadastrado para que se possa recuperar todos os dados referentes a este. Esta organização por projetos, é interessante para que se possa organizar dados de mais de um projeto no mesmo sistema, utilizando a mesma estrutura de software, evitando desta forma,trabalhos extras de configuração.

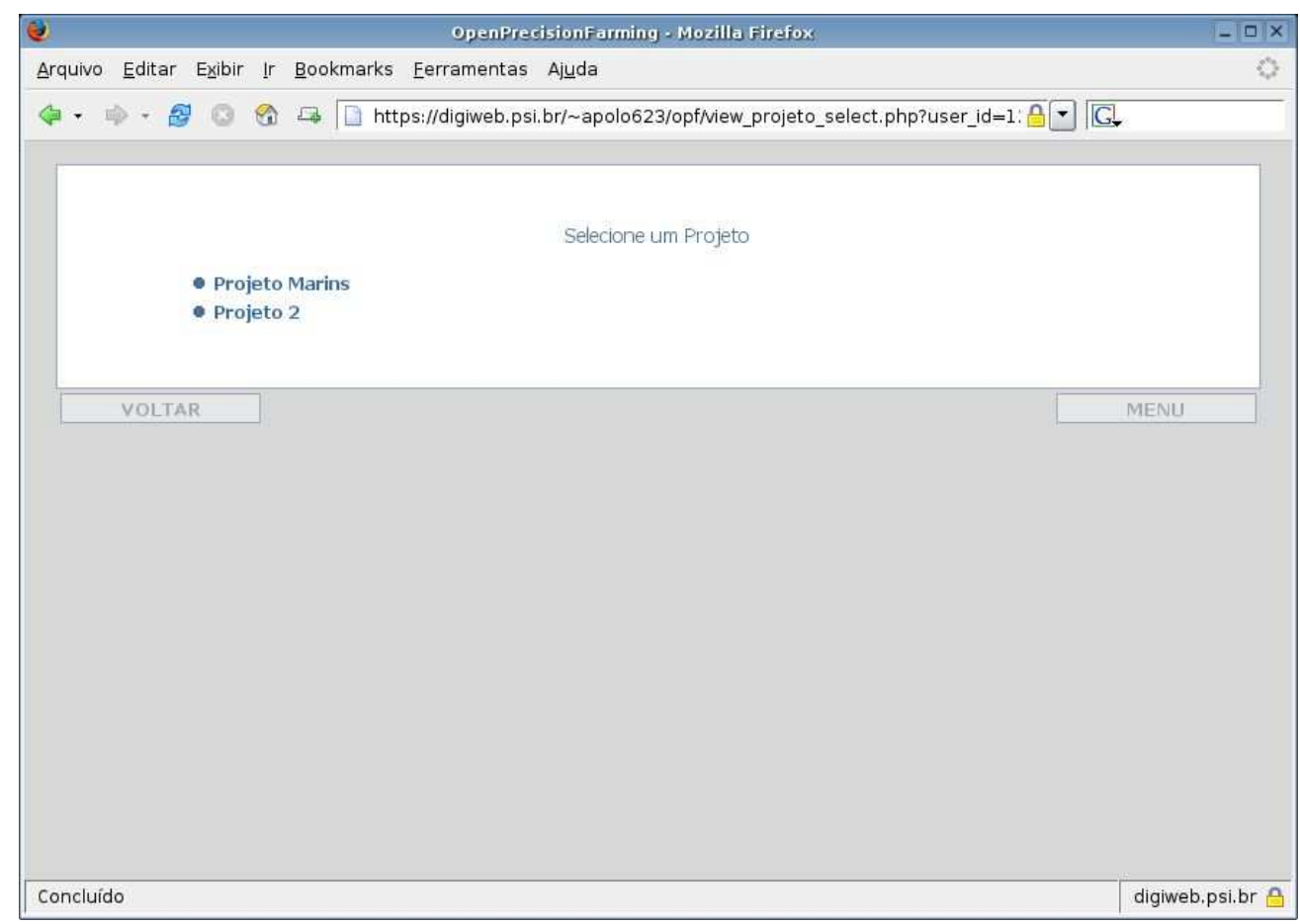

Figura 14 - Tela de seleção de projetos

$\mathrm{Na}$ figura 14 aparecem as duas opções de projetos para que o usuário escolha a opção que deseja visualizar. Após a seleção de um projeto, é visualizada a tela com um mapa básico da fazenda (figura 15) e também vê-se, do lado esquerdo, a caixa de seleção de layers que fazem parte desse projeto com os seus respectivos nomes. Esta 
caixa permite que ocorram seleções múltiplas com o fim de se combinar várias camadas e sobrepor diversos mapas. Na figura 16, os layers talhões e mata estão selecionados.

A imagem que é formada a partir da caixa de seleção e também pelos botões de navegação é criada dinamicamente. A cada mudança na caixa de seleção de layers, uma nova imagem é solicitada ao servidor, que executa as operações necessárias para criar a sua visualização.

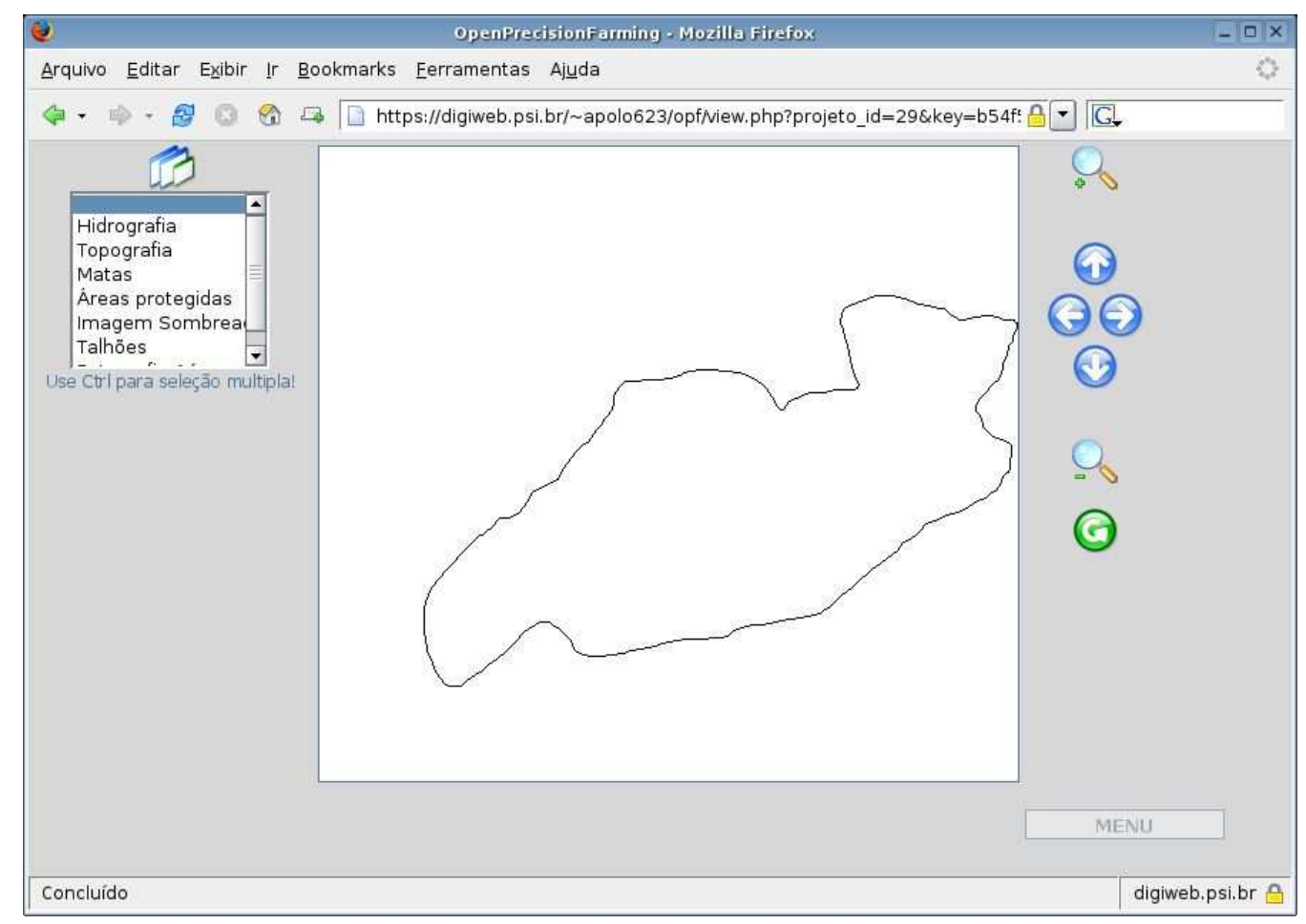

Figura 15 - Tela com mapa base do projeto selecionado

É possível combinar as diversas camadas como o mostrado na figura 16 onde os talhões foram combinados com uma fotografia aérea. Com o auxílio dos botões de navegação pode-se deslocar a visualização dos mapas e aplicar um zoom para se obter um detalhamento melhor. A figura 17 ilustra esse tipo de ação demonstrando um detalhamento do layer Talhões. 


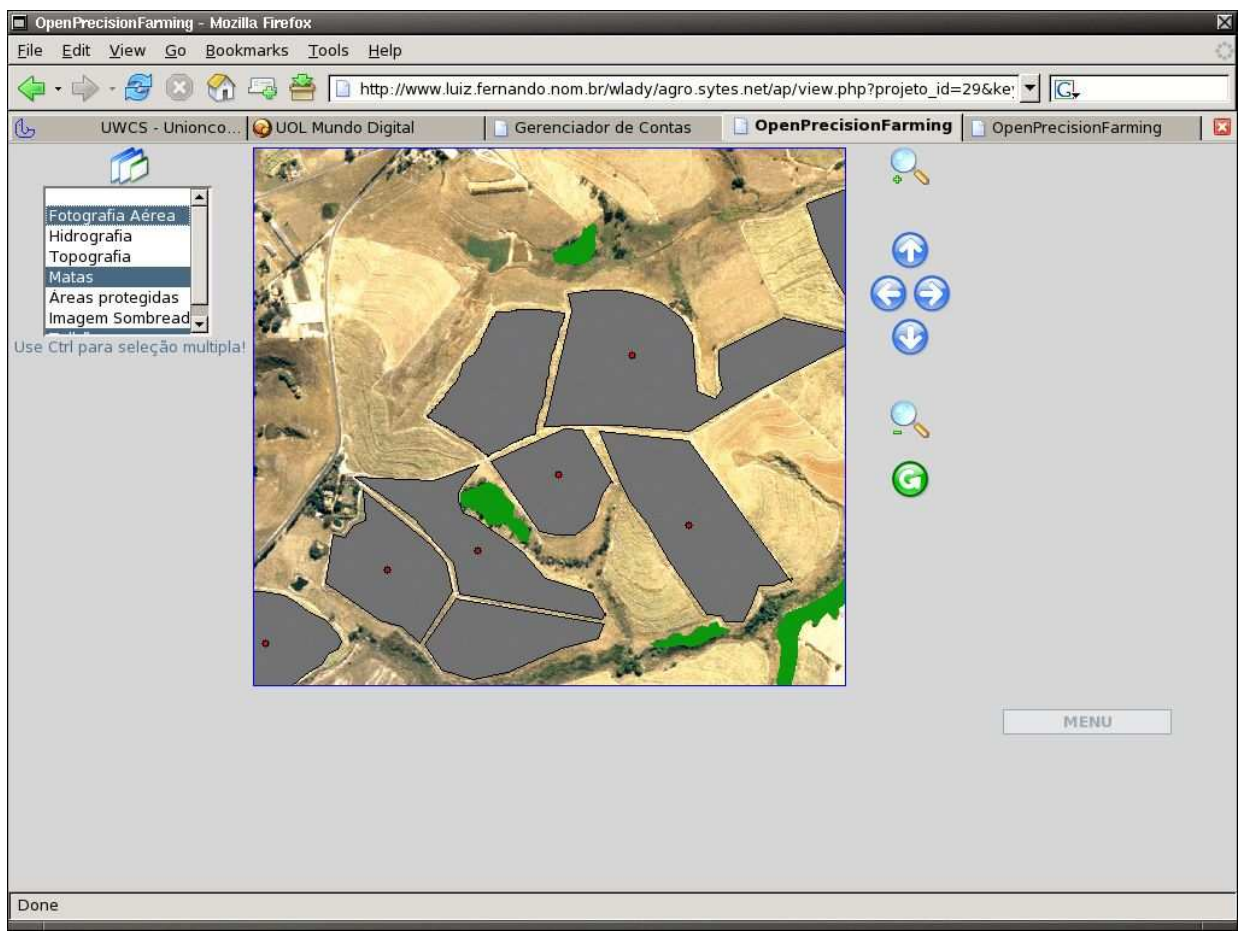

Figura 16 - Tela com imagem aérea sobreposta com mapa de topografia

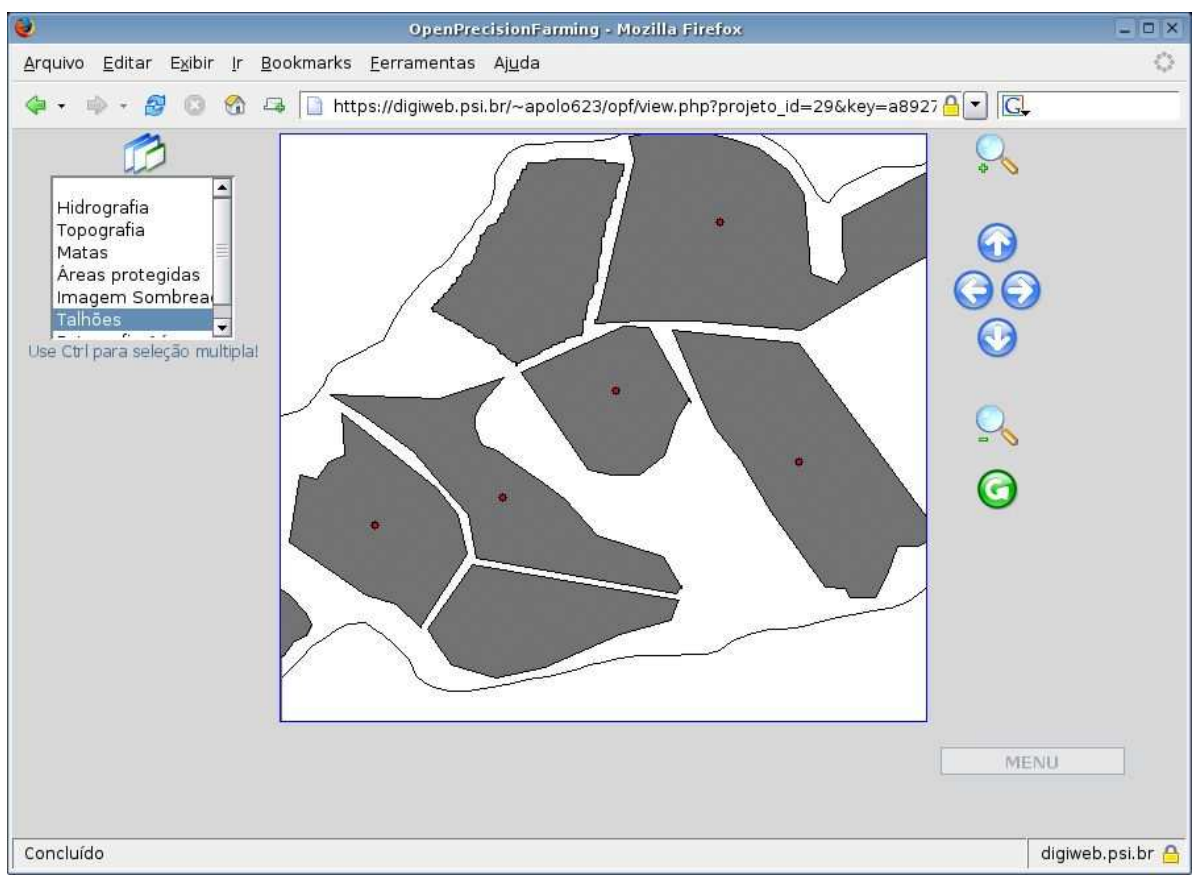

Figura 17 - Tela com mapa mostrando o layer de talhões selecionado e os pontos clicáveis para a seleção de uma talhão 
Para acessar os dados indexados aos talhões (layers, arquivos e históricos), é necessário que o usuário execute um click no ponto referente a um determinado talhão para selecioná-lo. Os talhões selecionáveis são percebidos pela presença dos pontos vermelhos e pela mudança do tipo de seta do mouse quando este passa por cima do ponto.

Selecionando um talhão específico (figura 18), uma caixa de diálogo cinza aparece no canteiro inferior esquerdo da tela. Nesta caixa é possível observar os seguintes elementos: o número do talhão que foi selecionado (Talhão 8), uma caixa de seleção contendo os novos layers e dois links em azul logo abaixo desta caixa (Históricos e Arquivos).

A nova caixa de seleção contém as opções dos mapas que foram indexados aos talhões. É possível selecioná-los clicando em seu nome, e visualizá-los na nova imagem que se forma.

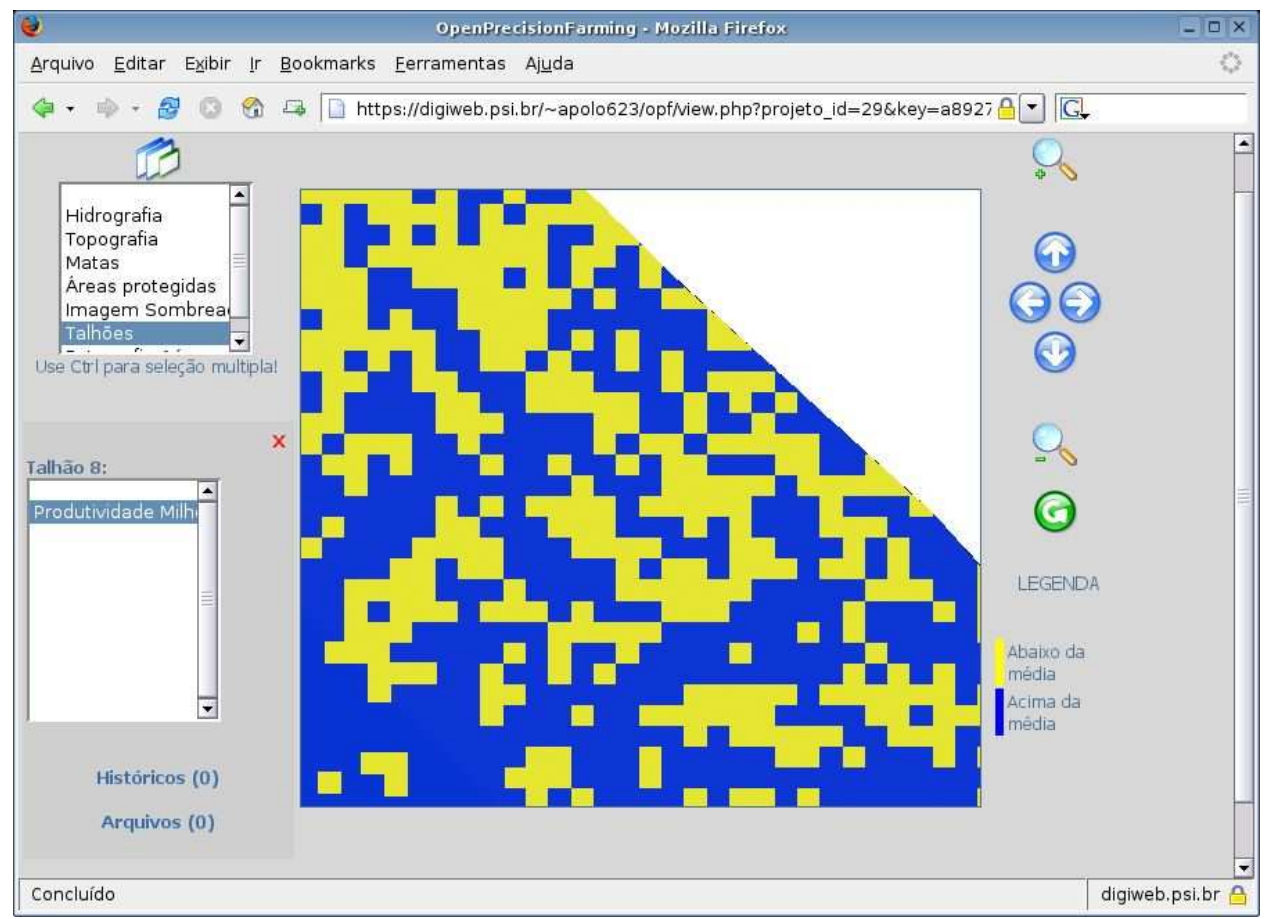

Figura 18 - Tela com mapa da produtividade de milho indexado ao talhão 8

Ao se clicar no link de históricos surge uma nova janela do navegador web com as opções para manipulação dos históricos (figura 19). Na tabela os históricos 
aparecem de forma resumida e podem ser acessados de forma completa clicando no link do histórico desejado.

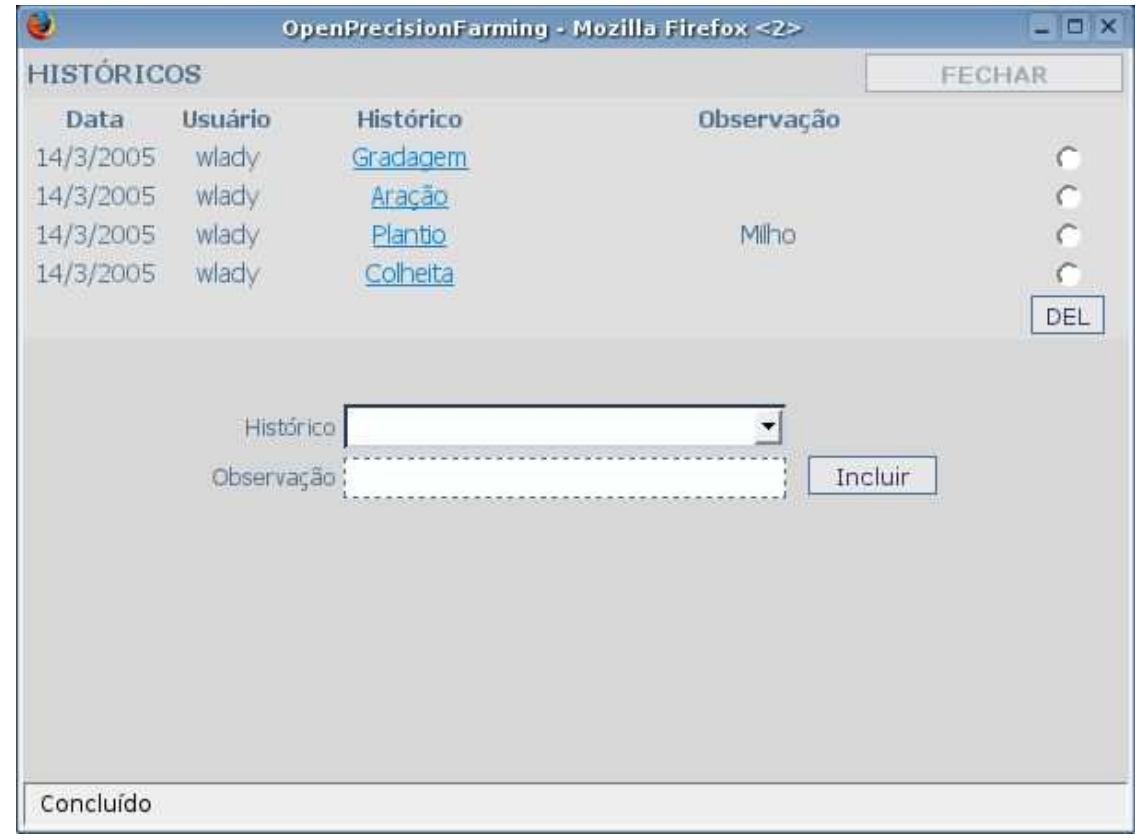

Figura 19 - Visualização da tela para inclusão e visualização de históricos indexados ao talhão

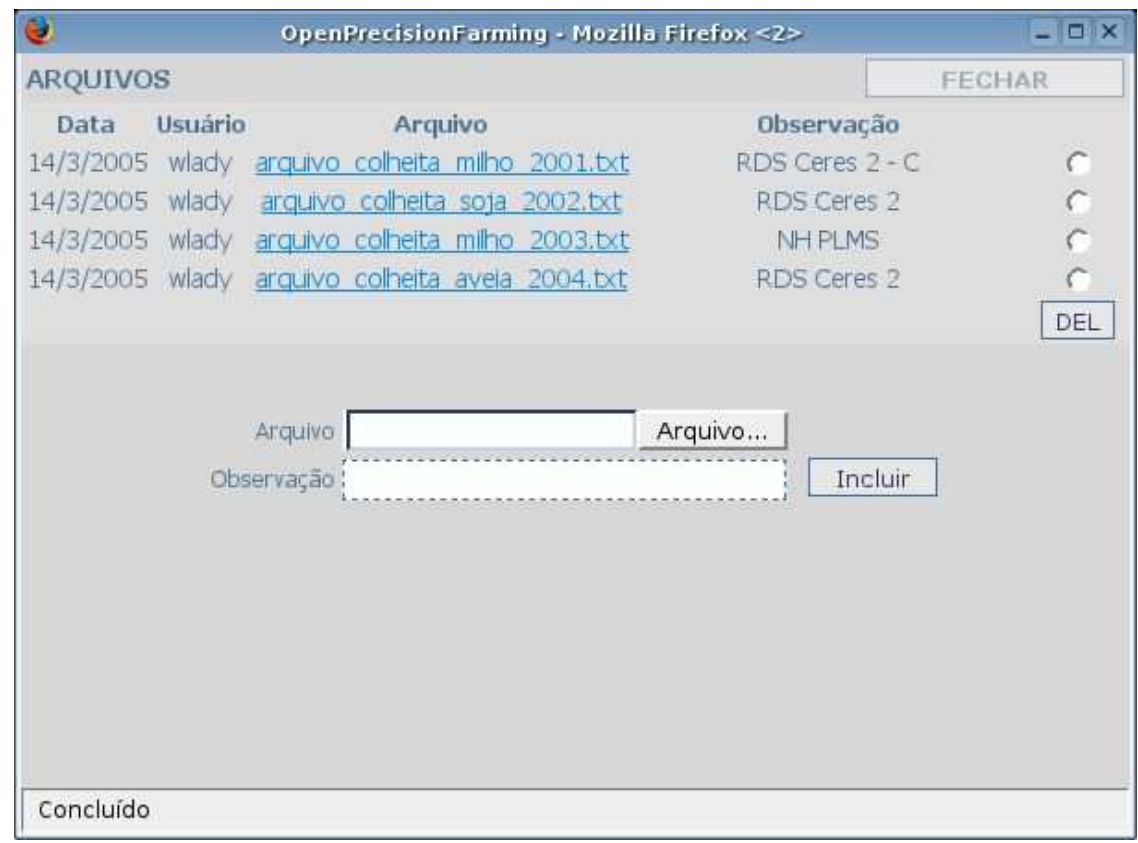

Figura 20 - Visualização da tela para inclusão e visualização de arquivos indexados ao talhão 
O comportamento do link Arquivos é semelhante ao link Históricos (figura 20). Ao clicar no link uma nova janela surge com as opções de arquivos indexados ao talhão. $\mathrm{O}$ arquivo pode ser visualizado clicando-se no link contendo o seu nome.

\subsection{Exemplos de uso de um usuário especialista}

Para o usuário especialista, temos o mesmo procedimento para a autenticação através da tela de login. Além da opção de visualização dos projetos na tela do menu principal (figura 21) temos também a opção de edição.

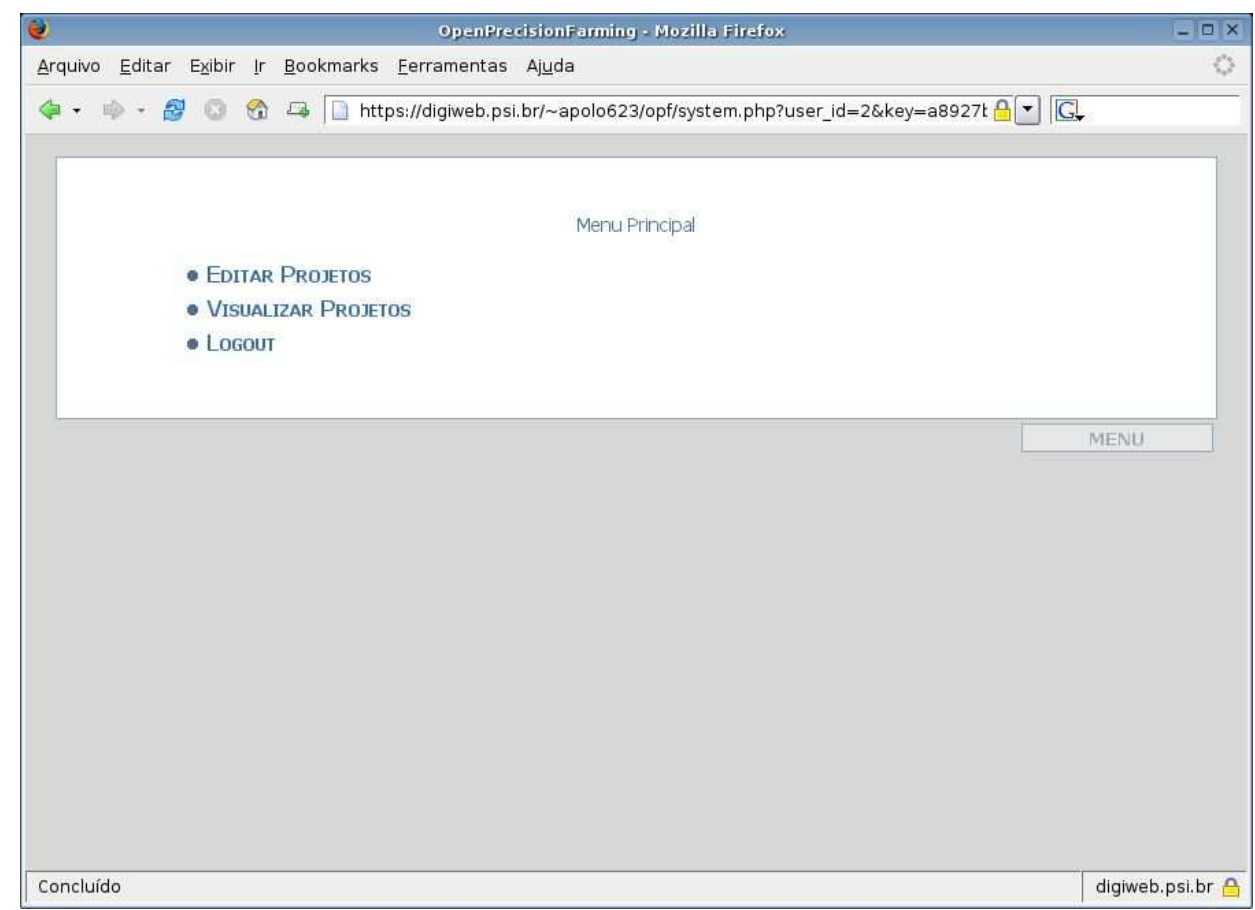

Figura 21 - Visualização da tela de opcões iniciais do sistema para o usuário especialista

Ao clicar no link "Editar Projetos" o usuário especialista é guiado a outra tela onde existem opções para incluir um novo projeto e para selecionar um projeto existente para edição. Ao selecionar um projeto, uma tela com opções para editar o projeto é apresentada (figura 22). 


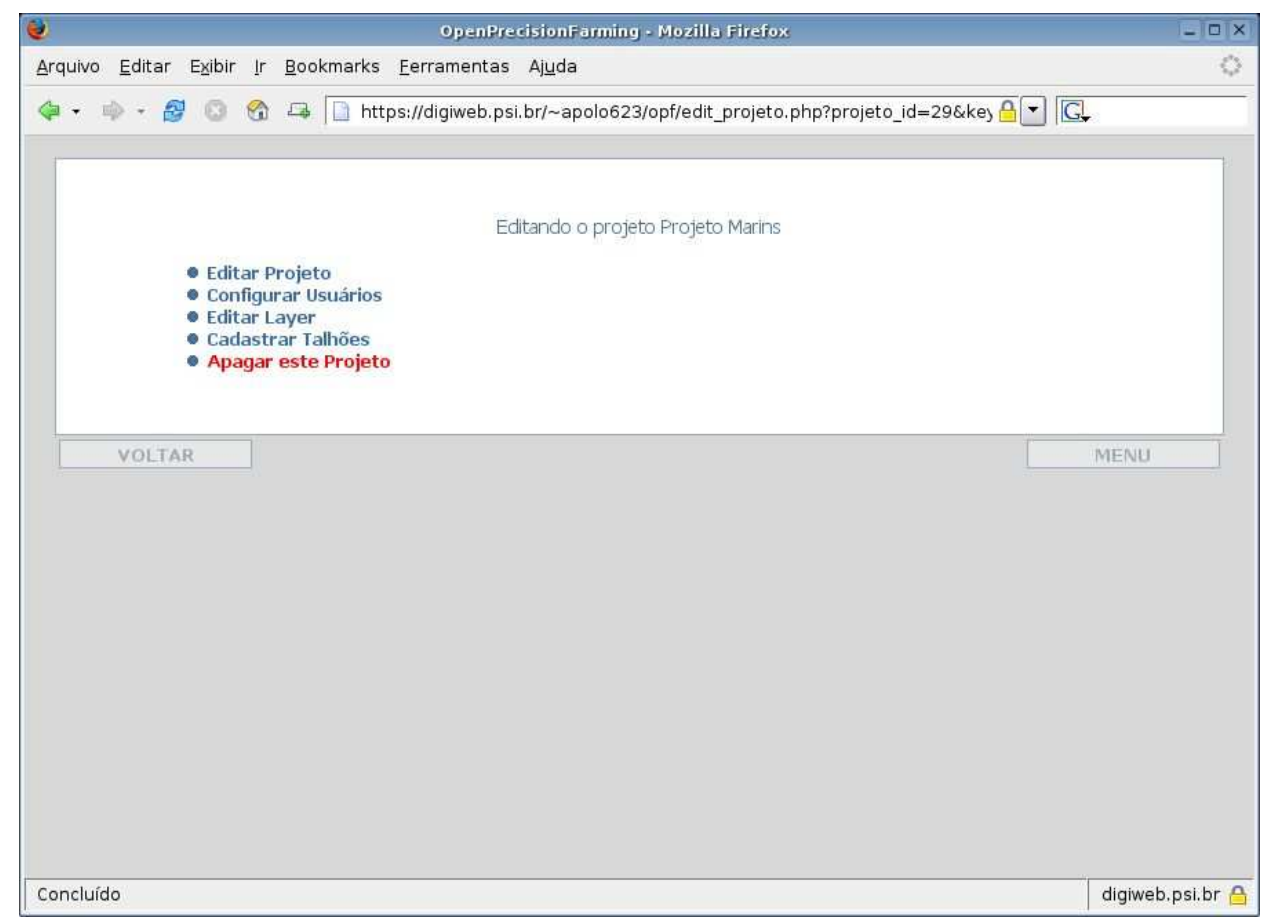

Figura 22 - Tela com opções de edição de projetos

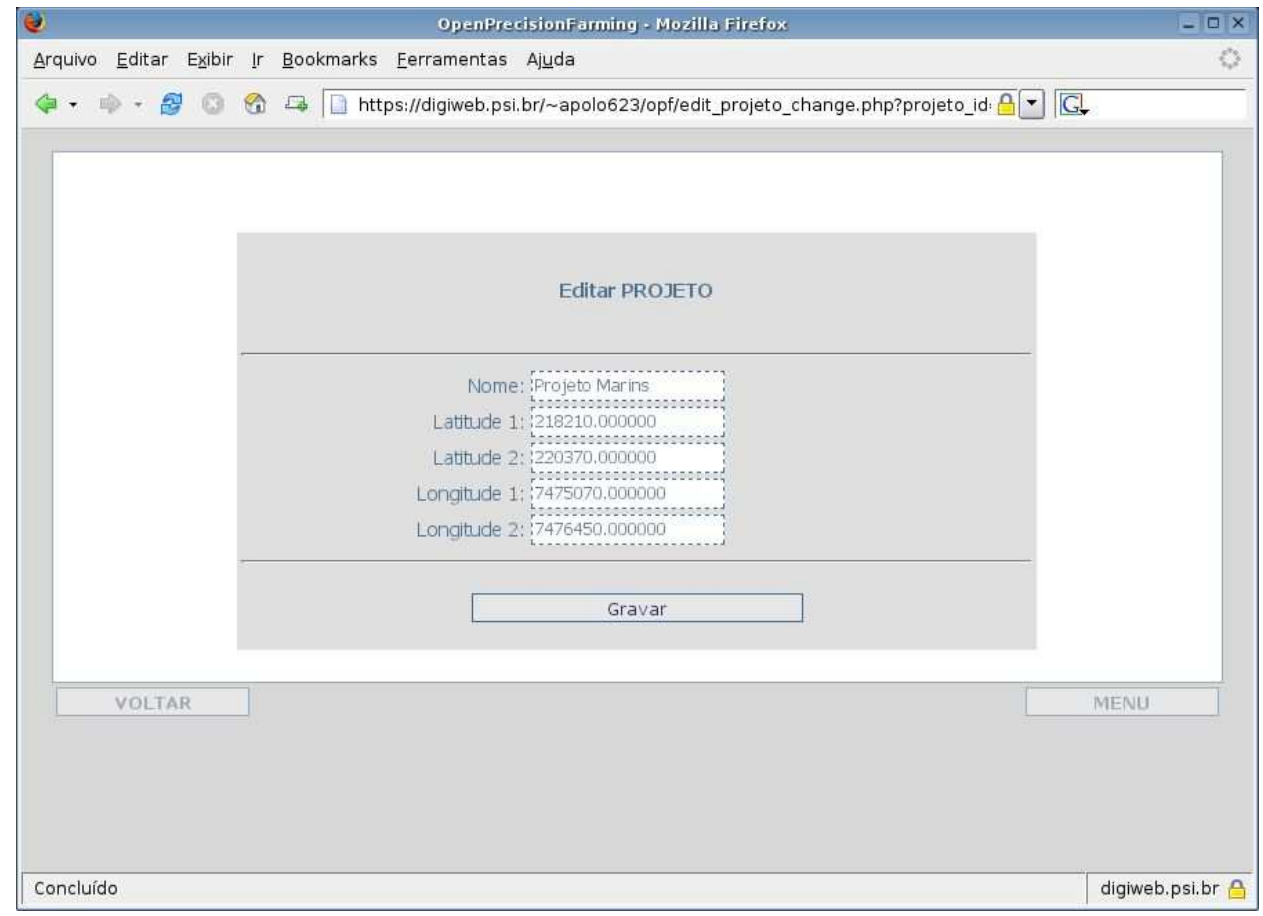

Figura 23 - Tela para edição dos dados do projeto 
Para que o módulo do mapscript possa ler os arquivos de dados vetoriais e imagens é necessário que se informe as coordenadas que representam um retângulo de visualização dos dados. Esses dados são inseridos em um formulário junto com o nome do projeto (figura 23).

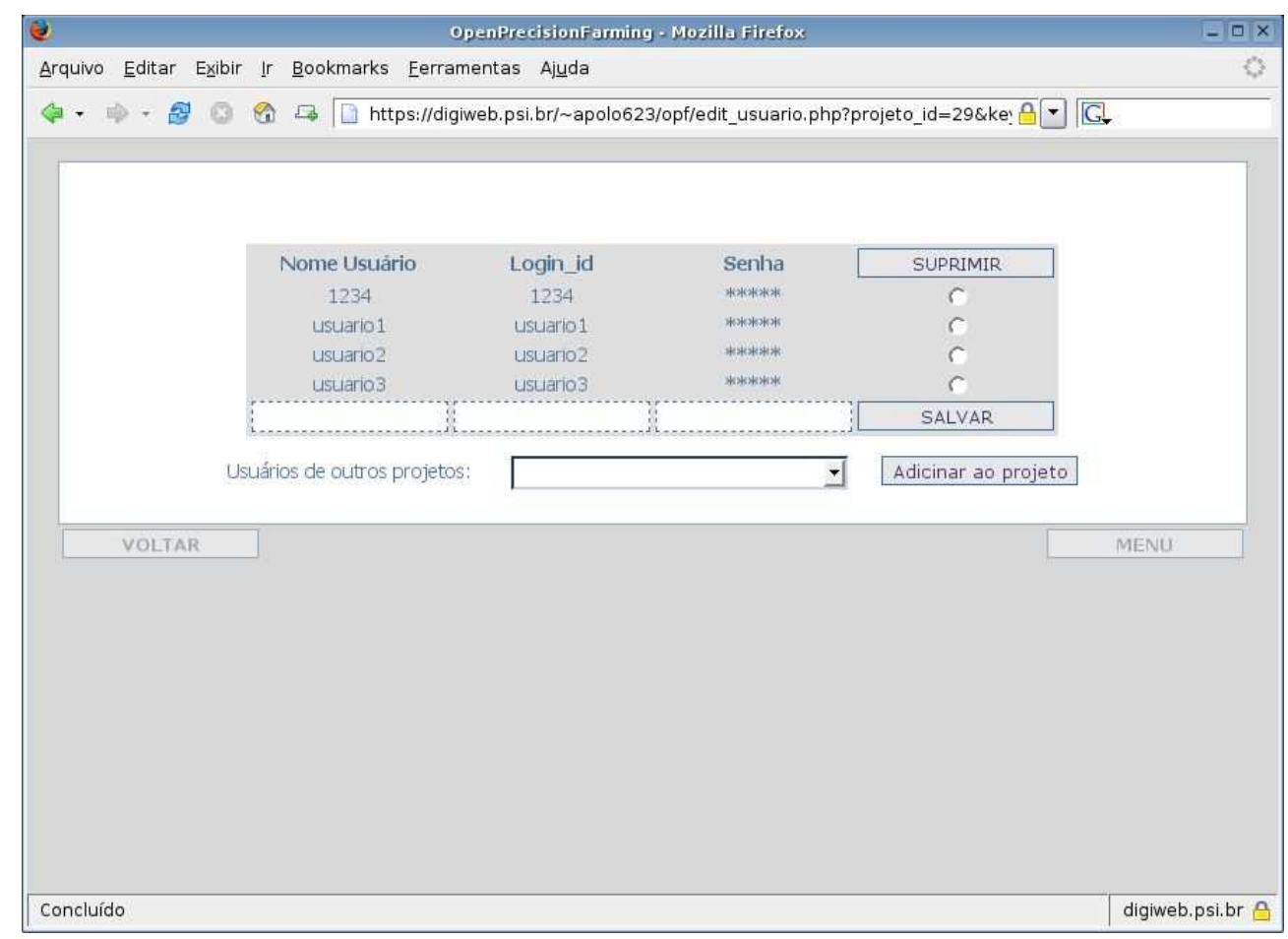

Figura 24 - Tela para inclusão de usuários que podem ter acesso ao projeto

O controle dos usuários por parte do usuário especialista, permite a inclusão de novos usuários não espacialistas para ter acesso ao projeto. Isso é feito a partir de um formuário onde é possível incluir novos usuários ao sistema ou então cadastrar usuários de outros projetos (figura 24). 


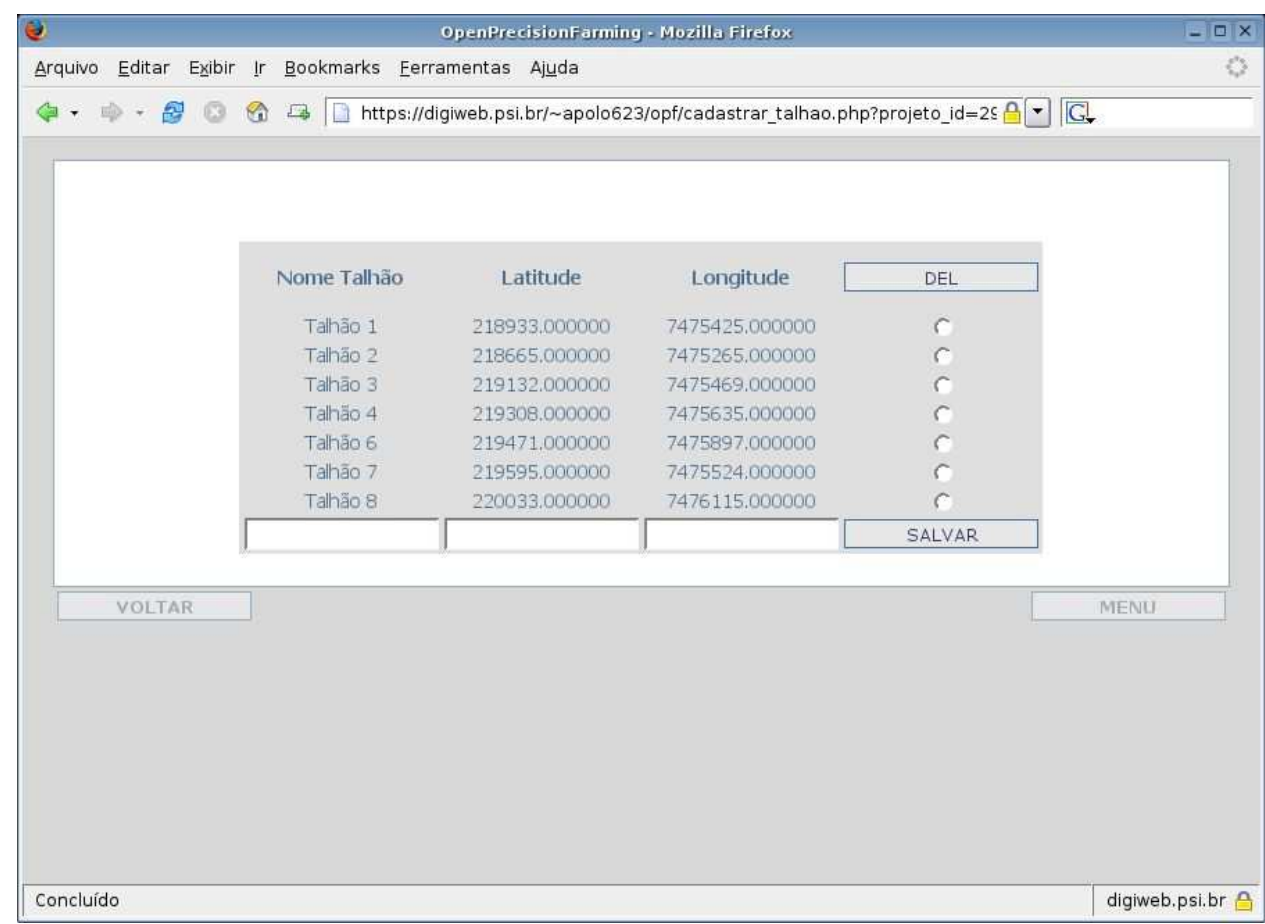

Figura 25 - Tela para cadastro dos talhões e coodernadas geográficas dos pontos centrais onde aparecerão os pontos clicáveis

Um outro ponto importante na criação do projeto é o estabelecimento das coordenadas dos pontos centrais dos talhões que servirão de link para acessar os dados indexados a ele. Esses pontos, depois de cadastrados, aparecem no mapa na forma de pontos vermelhos quando é selecionado o layer Talhões.

As opções de adição e exclusão de layers podem ser observadas na figura 26.

As opcões para edição e exclusão de arquivos de dados vetoriais (shape files) e imagens (no formato TIFF) podem ser observadas na figura 27. 


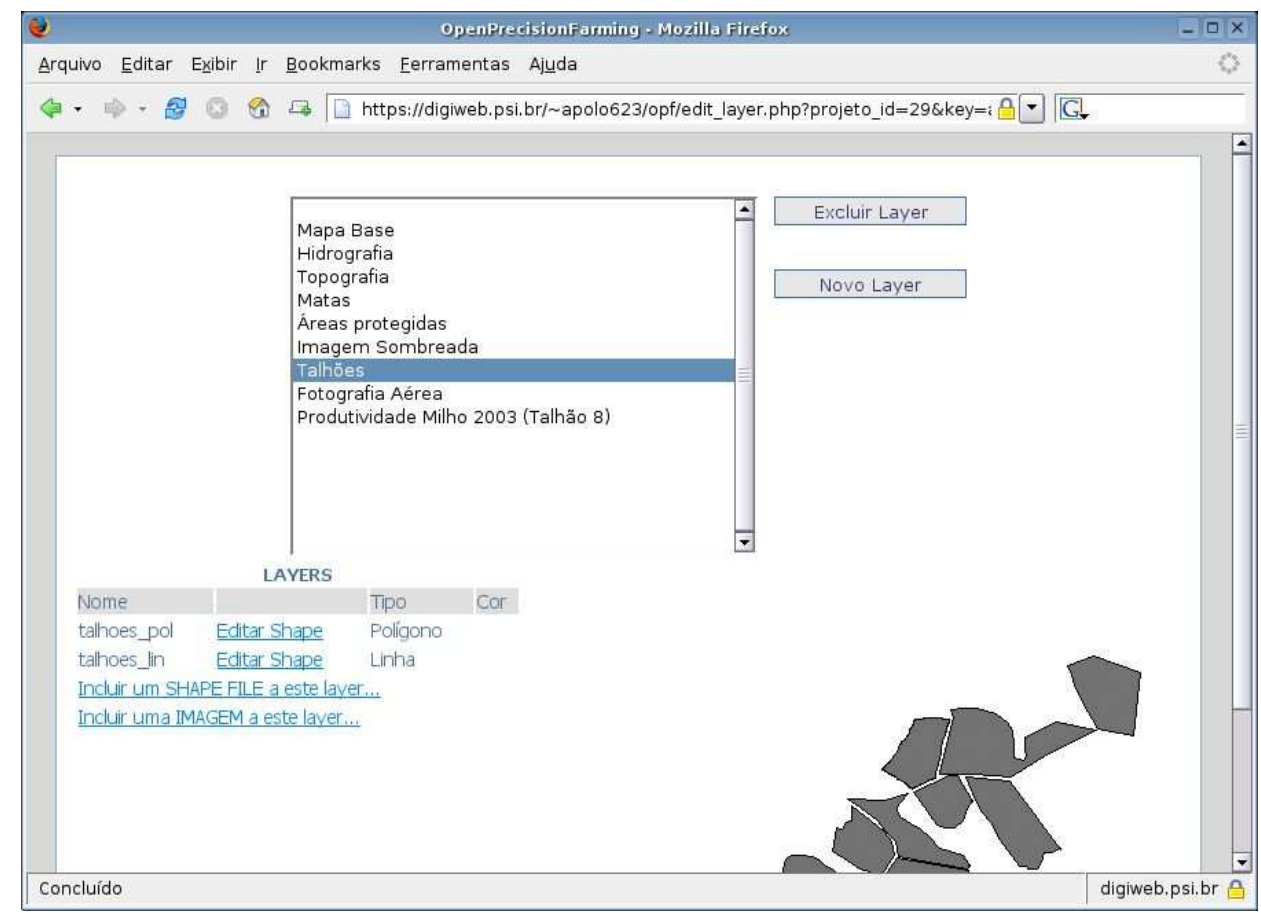

Figura 26 - Tela para a edição de layers

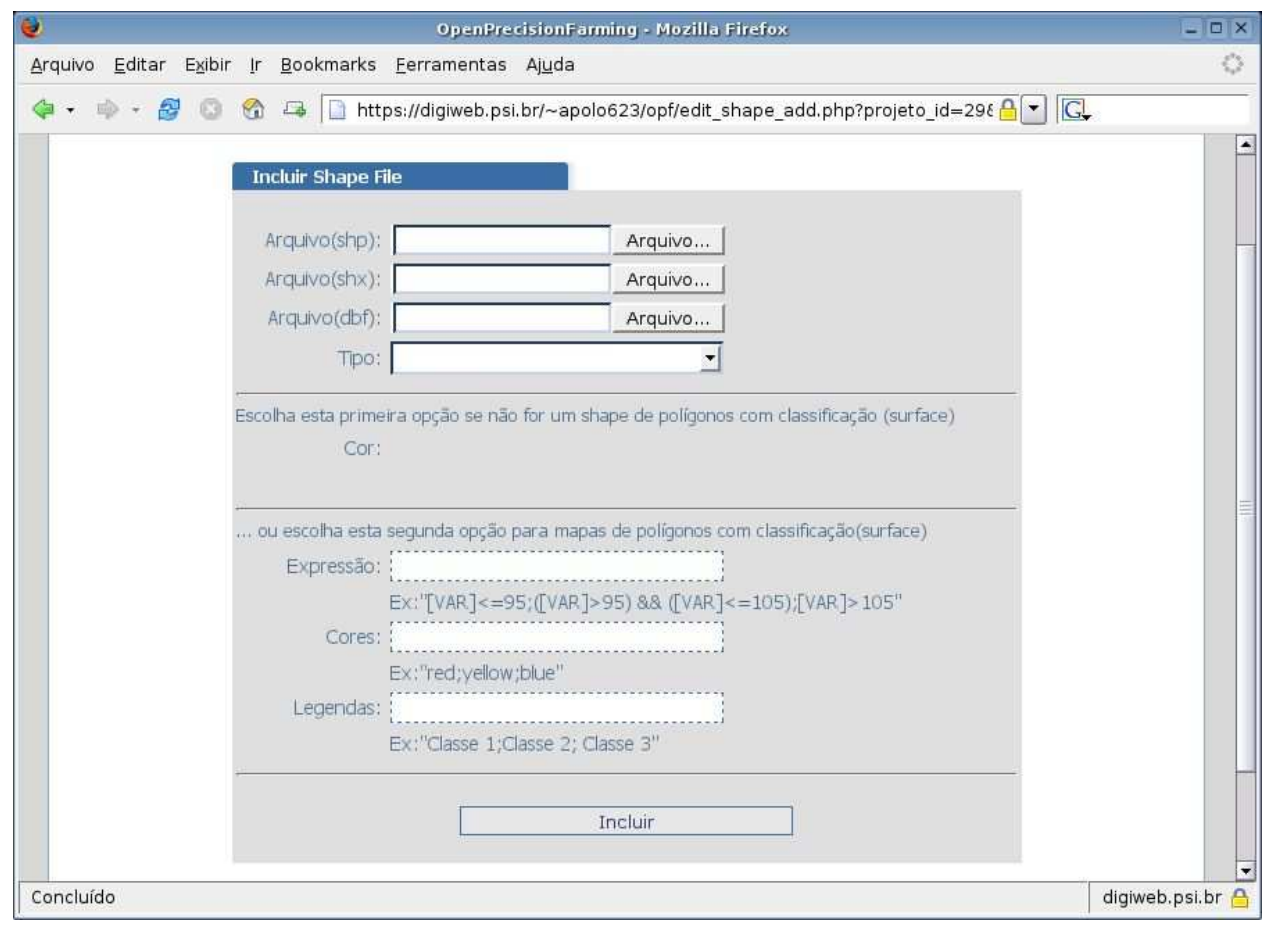

Figura 27 - Tela para incluir os arquivos com dados geográficos aos layers 
O modelo de ciclo de desenvolvimento de software utilizado neste trabalho foi o modelo em cascata. A utilização deste modelo possibilitou que o projeto fosse dividido em etapas bastante especializadas e que cada uma delas fosse formalizada e discutida a partir de seus diagramas e esquemas.

O uso da linguagem gráfica IDEF0 na fase de análise permitiu um melhor entendimento do problema a ser resolvido e desta forma pode-se elaborar, de forma mais sofisticada, a solução de software. Ela possibilitou que alguns detalhes do projeto, que dificilmente são visualizados quando se realiza uma análise de requisito somente textual, fossem destacados e discutidos antes de iniciar a fase de projeto.

O conceito de orientação a objetos apresentado no capítulo 2.5 permitiu que o software fosse pensado de forma modular e componentizada, permitindo desta forma, que novas funcionalidades sejam facilmente agregadas ao software pois sua estrutura não está organizada em cima de procedimentos (linguagem procedural) e sim em cima de objetos.

Essa estrutura baseada em objetos e a licença GPL deste projeto contribuem para que ele possa evoluir de forma colaborativa e ser utilizado por um grande número de pessoas e instituições.

O uso da arquitetura proposta, voltada ao uso da internet como meio de transmissão da informação e ao armazenamento de dados em bases remotas, é bastante promissor pois a Web é o serviço da internet mais disseminado.

Hoje praticamente todos os sistemas operacionais que são instalados em computadores desktop, provêem algum tipo de navegador Web, não necessitando da instalação de nenhum outro aplicativo para que o usuário acesse a internet. Isso permite que não apenas os sites de notícias e de empresas atinjam o público, mas também que diversas aplicações que antes eram instaladas nos desktops trabalhem de forma remota.

Desta forma, pode-se afirmar que a estrutura necessária para se ter acesso a um sistema baseado na web já está bastante consolidada e isso facilita a aceitação de novos softwares que operem neste ambiente, pois não é necessário que se introduza mudanças de conceitos ao usuário para utilizar o sistema. 
Um aspecto neste projeto que é bastante positivo para a aceitação do usuário é justamente a simplificação da arquitetura para acesso ao sistema, que utiliza somente a linguagem HTML para o tráfego de informações entre o servidor e o computador cliente. Como o computador do usuário executa operações apenas para formatar e apresentar as informações que estão em servidores $W e b$, muito pouco é exigido quanto à capacidade de processamento, e isso permite até o uso de computadores obsoletos para a execução da aplicação.

E esse obsoletismo de máquinas também ocorre, não somente com relação ao hardware, mas também com relação ao software dos computadores. Novamente, isso beneficia a utilização de sistemas baseados na web pois os navegadores antigos entendem a linguagem HTML da mesma forma que os mais recentes.

A velocidade da conexão torna-se um fator bastante importante para a usabilidade do sistema, pois toda a informação dos mapas é transferida na forma matricial(imagens), ao invés da forma vetorial. Em conexões do tipo banda larga a resposta do sistema será bastante rápida visto que cada imagem gerada representa menos que 30 kbytes (para uma resolução de 500 por 450 pontos) de informação. Em conexões discadas ou mesmos links dedicados que sejam mais lentos, uma maneira de se reduzir os impactos da baixa velocidade é a redução do tamanho da imagem gerada a cada requisição.

Outro ponto a ser levantado nesta discussão é a necessidade de recursos humanos especializados em tecnologia para a implementação do sistema nos servidores. Essa necessidade existe por que os subsistemas utilizados no servidor requerem algum tipo de configuração para o seu funcionamento. O servidor web apache, o módulo PHP apache e o servidor de banco de dados MySQL são bastante popularizados e sua instalação não possui grandes dificuldades para aqueles que possuam um conhecimento básico de tecnologias web. No entanto, a instalação do módulo mapscript do PHP é um pouco mais trabalhosa pois seu uso não é tão difundido quanto os outros subsistemas.

No entanto, esta necessidade não figura como um empecilho para a utilização do sistema pois existem diversas empresas no mercado que fornecem serviços de hospedagem de sites na internet, incluindo o uso da linguagem PHP, o banco de dados MySQL e até mesmo a instalação de módulos adicionais do PHP (como é o caso 
do Mapscript). Além do mais, a configuração de apenas um servidor web é o bastante para que muitos projetos possam ser gravados no sistema.

Em contraponto à simplificação do sistema para o usuário não especialista temos uma maior carga de responsabilidades para o usuário especializado no sentido de ter que realizar as seguintes tarefas:

- selecionar de forma criteriosa as informações a serem incluídas em cada layer (camada do mapa) do projeto;

- cadastrar as coordenadas geográficas de cada talhão para que se possa criar o ponto clicável e desta forma indexar as informações a este layer;

- cadastrar os usuários que terão acesso a este projeto.

Muitas outras características poderiam ser futuramente acrescentadas a este sistema em implementações futuras, no sentido de complementar o conceito de interatividade para projetos de Agricultura de Precisão. Uma delas seria a funcionalidade de trocas de mensagens entre o usuário especialista e o não especialista para que estes pudessem discutir os mapas e trocar idéias. 


\section{CONCLUSÕES}

Para auxiliar o processo de compartilhamento de geoinformações de Agricultura de Precisão foi proposto e desenvolvido um sistema de informação que opera via internet para organizar, armazenar e distribuir essas informações de forma a possibilitar que diversos usuários possam acessá-las de forma fácil e com a utilização de apenas um navegador web.

O objetivo principal deste trabalho foi o entendimento dos aspectos envolvidos na construção deste sistema a partir da abordagem teórica, passando pela sua proposição e finalizando com o seu desenvolvimento.

A abordagem teórica permitiu uma melhor compreensão dos conceitos envolvidos no desenvolvimento do sistema e possibilitou que fosse atingido o objetivo principal.

O sofware desenvolvido possibilita que se utilize o sistema para as seguintes atividades por parte dos usuários especializados:

- a criação e edição de novos projetos;

- a inclusão e exclusão de mapas de talhões e o cadastramentos de pontos clicáveis para que se possa indexar mapas estes talhões;

- a inclusão e exclusão de mapas vetoriais ou raster;

- a inclusão de usuários que poderão ter acesso a cada projeto.

Por parte do usuário não especializado o sistema permite:

- a visualização dos mapas e imagens;

- a seleção de um talhão específico através dos pontos clicáveis;

- a visualização de mapas específicos indexados a este talhão;

- a inclusão de históricos indexados ao talhão selecionado;

- a inclusão de arquivos indexados ao talhão selecionado. 
Com relação aos objetivos específicos, todos foram atingidos.

O sistema desenvolvido permite que o usuário possa interagir com mapas utilizando-se apenas de navegadores $W e b$, sem a necessidade instalação de nenhum software adicional no computador do usuário.

Esse sistema também permite que o usuário grave históricos e arquivos indexados a talhões de produção.

O método de interação com mapas baseado na criação dinâmica de pontos clicáveis sobre uma imagem mostrou-se funcional para a indexação das informações aos talhões da propriedade.

Os subsistemas envolvidos na solução proposta (servidor web, modulos php, módulo mapscript, banco de dados Mysql) possibilitaram o desenvolvimento de um sistema onde não existe custos de licenciamento de softwares pois todos eles são softwares livres.

Os resultados desse estudo mostraram-se promissores para a construção de sitemas baseados de geoinformação na web, inclusive para outras áreas além da agricultura de precisão.

Este trabalho, que foi desenvolvido sob a licença GPL, pretende ser um ponto de partida para que novos projetos incorporem funcionalidades ao sistema.

Por fim, como já mencionado anteriormente, a implementação do projeto teve como resultados o código fonte do sistema que é constituído por 27 arquivos de script PHP, que totalizam 2696 linhas. 


\section{REFERÊNCIAS BIBLIOGRÁFICAS}

BALASTREIRE, L.A. Agricultura de precisão. Piracicaba: O autor, 2001. 1v.

BLACKMORE, S.B. The role of yield maps in Precision Farming. Silsoe, 2003. 162p.

Thesis (PhD) - Cranfield University.

BOOCH, G.; RUMBAUGH, J.; JACOBSON, I. UML: guia do usuário. Trad de F.F. da

Silva. Rio de Janeiro: Campus, 2000. 472p.

BURROUGH, P.A.; McDONNELL, R.A. Principles of geographical information

systems. New York: Oxford University Press, 1998. 344p.

CÂMARA G. Modelos, linguagens e arquiteturas para bancos de dados geográficos.

São José dos Campos, 1995. 264p. Tese (Doutorado) - Instituto Nacional de

Pesquisas Espaciais.

CÂMARA G.; MEDEIROS J.S. Geoprocessamento para projetos ambientais. São

José dos Campos: INPE, 1996. 246p.

CÂMARA, G.; MEDEIROS, J.S. Princípios básicos em geoprocessamento. In: ASSAD,

E.D.; SANO, E.E. Sistemas de informações geográficas: aplicações na agricultura. Brasília: EMBRAPA, 1998. cap.1, p.3-11.

CASTAGNETTO, J.;RAWAT, H.; SCHUMANJ, S.; SCOLlO, C.; VELIATH, D.

Profissional PHP - programando. São Paulo: Makron Books, 1999. 770p.

CODD, E.F. The relational model for database management. 2.ed. New York:

Addson-Wesley, 1990. 538p.

ITRI, M. Internet 2: a próxima geração. São Paulo: Market Books, 1999. 352p.

IDEF. IDEF0 Overview. www.idef.com/idef0.html (15 jan. 2005).

KIMBALL, R.; MERZ, R. Data webhouse: construindo o data warehouse para a web.

Trad. de E. Furmankiewicz. Rio de Janeiro: Ed. Campus, 2000. 357p. 
KLEINER, R.M. Atlas digital interativo: protótipo para disponibilização via www. Presidente Prudente, 2000. 222p. Dissertação (Mestrado) - Faculdade de Ciências e Tecnologia de Presidente Prudente.

MANGABEIRA, J.A.C.; CARVALHO, C.A. de; OSHIRO, O.T. Disponibilização de informações do uso das terras em Holambra com WebGis (compact disc). In: CONGRESSO E FEIRA PARA USUÁRIOS DE GEOPROCESSAMENTO, 9., São Paulo, 2003. Anais. Curitiba: s. ed., 2003.

MAPSERVER. Mapserver homepage. http://mapserver.gis.umn.edu/index.html (15 jan. 2005).

MELO, R.N.; SILVA, S.D.; TANAKA, A. Banco de dados em aplicações cliente servidor: distribuição de processamento, fundamentos de bancos de dados, bancos de dados distribuídos e bancos de dados distribuídos heterogêneos. Rio de Janeiro: Infobook, 1998. $255 \mathrm{p}$.

MIRANDA, J.I. Publicando mapas na web: servlets, applets ou CGI? Campinas: Embrapa Informática Agropecuária, 2003. 38 p. ( Documentos, 28)

NETCRAFT. January $2005 \quad$ Web $\quad$ Server http://news.netcraft.com/archives/2005/01/01/january_2005_web_server_survey.html (11 jan. 2005)

OSSES, J.R.; PAIVA, J.A.C.; CÂMARA, G. Arquiteturas cliente-servidor para bibliotecas geográficas digitais. In: WORKSHOP BRASILEIRO DE GEOINFORMÁTICA, 2., São Paulo, 2000. Anais. São Paulo: s. ed., 2000. p. 60-67. PEREZ, C.R.; BATISTA, C.F.; SALGADO, A.C. BDGEO: modelagem, implementação e visualização de dados geográficos (compact disc). In: CONGRESSO E FEIRA PARA USUÁRIOS DE GEOPROCESSAMENTO, 3., Curitiba, 1997. Anais. Curitiba: s. ed., 1997.

PRESSMAN, R. S. Engenharia de software. Trad. de J.C.B. Dos Santos. 5.ed. Rio de Janeiro:McGraw-Hill, 2002. 846 p.

SARAIVA, A.M. Tecnologia da informação na agricultura de precisão e biodiversidade: estudos e proposta de utilização de web services para desenvolvimento e integração de sistemas. São Paulo, 2003. 187p. Tese (Livre-Docência) - Escola Politécnica, Universidade de São Paulo. 
SCHIMIGUEL, J.; BARANAUSKAS, M.C.C. Avaliando sinais em interfaces para Sistemas de Informação Geográfica. Campinas: UNICAMP, 2001. 15p. (Relatório Técnico ).

SILVA, L.; REMOALDO, P. Introdução à internet. Lisboa: Ed. Presença, 1995. 222p.

SILVA, R. Bancos de dados geográficos: uma análise das arquiteturas dual (Spring) e integrada (Oracle Spatial). São Paulo, 2002. 137p. Dissertação (Mestrado) - Escola Politécnica, Universidade de São Paulo.

SOMMERVILLE, I. Engenharia de software. 6.ed. São Paulo: Makron Books, 2003. $591 \mathrm{p}$.

THOMÉ, R. Interoperabilidade em geoprocessamento: conversão entre modelos conceituais de sistemas de informação geográfica e comparação do padrão OpenGIS. São José dos Campos, 1998. 196 p. Dissertação (Mestrado) - Instituto Nacional de Pesquisas Espaciais.

TSCHIEDEL, M.; FERREIRA, M.F. Introdução à agricultura de precisão: conceitos e vantagens. Ciência Rural, v.32, p.159-163, 2002.

UCHOA, H.N.; FERREIRA, P.R. Geoprocessamento com software livre. http://www.geolivre.org.br (15 jan. 2005).

W3C. HTML 4.01 specification W3C recommendation 24 December 1999. http://www.w3.org/TR/html401 (03 dez. 2004)

WAGNER. J.O. FreeGIS software and free geo-data: conversion tools, freeGIS consortium. http://www.freegis.org. (20 jan. 2005).

WINBLAD, A.L.; EDWARDS, S.D.; KING, D.R. Software orientado ao objeto. São Paulo: Makron Books, 1990. 309 p. 